\title{
Topography induced spatial variations in diurnal cycles of assimilation and latent heat of Mediterranean forest
}

\author{
C. van der Tol ${ }^{1}$, A. J. Dolman ${ }^{1}$, M. J. Waterloo ${ }^{1}$, and K. Raspor ${ }^{2}$ \\ ${ }^{1}$ Dept. of Hydrology and Geo-Environmental Sciences, Vrije Universiteit Amsterdam, The Netherlands \\ ${ }^{2}$ Dept. of Civil and Geodetic Engineering, University of Ljubljana, Slovenia
}

Received: 4 September 2006 - Published in Biogeosciences Discuss.: 6 October 2006

Revised: 8 January 2007 - Accepted: 13 February 2007 - Published: 22 February 2007

\begin{abstract}
The aim of this study is to explain topography induced spatial variations in the diurnal cycles of assimilation and latent heat of Mediterranean forest. Spatial variations of the fluxes are caused by variations in weather conditions and in vegetation characteristics. Weather conditions reflect short-term effects of climate, whereas vegetation characteristics, through adaptation and acclimation, long-term effects of climate. In this study measurements of plant physiology and weather conditions are used to explain observed differences in the fluxes. A model is used to study which part of the differences in the fluxes is caused by weather conditions and which part by vegetation characteristics. Data were collected at four experimental sub-Mediterranean deciduous forest plots in a heterogeneous terrain with contrasting aspect, soil water availability, humidity and temperature. We used a sun-shade model to scale fluxes from leaf to canopy, and calculated the canopy energy balance. Parameter values were derived from measurements of light interception, leaf chamber photosynthesis, leaf nitrogen content and ${ }^{13} \mathrm{C}$ isotope discrimination in leaf material. Leaf nitrogen content is a measure of photosynthetic capacity, and ${ }^{13} \mathrm{C}$ isotope discrimination of water use efficiency. For validation, sap-flux based measurements of transpiration were used. The model predicted diurnal cycles of transpiration and stomatal conductance, both their magnitudes and differences in afternoon stomatal closure between slopes of different aspect within the confidence interval of the validation data. Weather conditions mainly responsible for the shape of the diurnal cycles, and vegetation parameters for the magnitude of the fluxes. Although the data do not allow for a quantification of the two effects, the differences in vegetation parameters and weather among the plots and the sensitivity of the fluxes to them suggest that the diurnal cycles were more strongly affected by spatial variations in vegetation parameters than by meteo-
\end{abstract}

Correspondence to: C. van der Tol

(tol@itc.nl) rological variables. This indicates that topography induced variations in vegetation parameters are of equal importance to the fluxes as topography induced variations in radiation, humidity and temperature.

\section{Introduction}

The problem of modelling the energy balance of the surface and the exchange of carbon dioxide and water between surface and atmosphere today is not so much the understanding of the physical processes itself, but rather the application of the processes understanding at the desired spatial scale and the estimation of parameter values. Surface exchange models for water and carbon dioxide have developed in the last 30 years from simple conceptual models towards more accurate descriptions of the soil-vegetation-atmosphere system. This development is driven by an increasing emphasis on the carbon balance as a focal point of atmospheric modelling beside the energy and water balance (Sellers et al., 1997). A great improvement has been the discovery of a close relation between stomatal conductance and photosynthesis rate (Wong et al., 1979), and the consequent integration of the descriptions of transpiration and photosynthesis (Lloyd et al., 1995; Harley and Baldocchi, 1995; Tuzet et al., 2003). This development has lead to the need to estimate vegetation parameters and to scale from leaf to canopy level.

Both weather conditions and vegetation characteristics affect the fluxes of water and carbon from a vegetated surface. The effect of vegetation is in fact an indirect effect of climate: the evolution of vegetation depends on long-term climate (Hetherington and Woodward, 2003). Thus, we can distinguish short term (or direct) from long-term (or indirect) effects of climate. Short term effects are those of radiation, temperature and vapour pressure deficit, and long term effects those of photosynthetic capacity and regulation of stomatal conductance. Both weather conditions and vegetation

Published by Copernicus GmbH on behalf of the European Geosciences Union. 
characteristics vary spatially, and are most likely correlated in some way. By considering these two time scales separately, we may arrive at better understanding of the spatial and temporal variability of parameter values and fluxes.

This study focuses on estimating the effects of those spatial variations in weather conditions and vegetation characteristics on the diurnal cycle of latent heat flux. The two aims of the study are (1) to translate vegetation characteristics into diurnal cycles of photosynthesis and transpiration, and (2) to separate the effects of weather conditions and vegetation characteristics on the diurnal cycles of assimilation and latent heat flux using a sensitivity analysis. The focus is not on the processes of adaptation or acclimation that lead to specific vegetation characteristics, but rather on the effects of vegetation characteristics (long time effects of climate) and weather conditions (short time effects of climate) have on the fluxes.

Data were collected during a field campaign at four experimental plots in natural broadleaf sub-Mediterranean forests in Slovenia, which contrast in local hydrological and climate conditions, aspect and vegetation composition. Due to the complexity of the terrain, no area-integrated measurement of the fluxes could be made. Two other approaches were used instead, one based on leaf nitrogen content, isotope discrimination and leaf area index, and another based on sap flux density and sapwood area. In the first approach, vegetation characteristics which govern the fluxes were measured, and the fluxes calculated from weather conditions using a model. In the second approach, sap flux was measured directly and continuously. These sap flux measurements were used as validation of the model. In this way, it was tested whether transpiration can be predicted from leaf parameters. A sensitivity analysis of the model was performed to separate the effects of vegetation parameters and weather conditions on surface conductance and the fluxes of carbon dioxide and water.

The model calculates photosynthesis, the energy balance and the fluxes of carbon dioxide and water from leaf parameters for the sun and shaded leaves separately. The model is similar to existing models for scaling of fluxes from leaf to canopy (Leuning et al., 1995). For parameterisation, leaf nitrogen content, ${ }^{13} \mathrm{C}$ isotope discrimination of leaf material, leaf chamber photosynthesis and leaf area index measurements were used.

\section{Method and materials}

\subsection{Model description}

Two important processes in integrated models for photosynthesis and the energy balance are carboxylation of carbon dioxide in leaves and transport of carbon dioxide from the air into leaves. Transport of carbon inevitably involves loss of water by transpiration, which travels along the same path as carbon but in opposite direction. The uptake of car- bon dioxide and the loss of water by transpiration is regulated by stomatal conductance. The two most important characteristics of vegetation to describe these processes are unquestionably the photosynthetic capacity and the way in which vegetation regulates stomatal conductance (Farquhar and Sharkey, 1982).

The model we used to calculate the fluxes of water and carbon dioxide consists of three components: photosynthesis and transpiration at leaf level as a function of biochemical parameters, scaling of the fluxes to canopy level, and an energy balance of the canopy. At leaf level, diffusion equations, a biochemical model for photosynthesis (Farquhar et al., 1980) and the model for optimal stomatal control of Cowan (1977) are used. Scaling from leaf to canopy is carried out with a two-leaf model that distinguishes between a sunlit and a shaded fraction of leaves. An energy balance of the canopy is used to solve canopy temperature, which in turn affects the processes in the leaves. Figure 1 shows the structure of the model. In what follows, the three components of the model are presented.

Water and carbon dioxide move by diffusion in opposite directions between the stomata and the air. Water evaporates from the cell walls, and travels from the stomata to the air, whereas carbon dioxide travels from the air, via the stomata into the mesophyll, where it is reduced to sugars by the chemical reactions in the Calvin cycle. If the resistance for transport of carbon dioxide from the stomata to the mesophyll is neglected, then the diffusion equations can be written as:

$$
E=1.6 g \frac{\rho_{a}}{M_{a}} \frac{e_{i}-e_{a}}{p}=1.6 \mathrm{~g} D
$$

$A=g\left(C_{a}-C_{i}\right)$

where $E$ is evaporation and $A$ assimilation $\left(\mathrm{mol} \mathrm{m}^{-2} \mathrm{~s}^{-1}\right), g$ the effective aerodynamic and stomatal conductance $\left(\mathrm{m} \mathrm{s}^{-1}\right)$, $e_{i}$ and $e_{a}$ the vapour pressure in the intercellular spaces and in the ambient air $(\mathrm{Pa})$, respectively, $p$ atmospheric pressure $(\mathrm{Pa}), \rho_{a}$ specific mass of air $\left(\mathrm{kgm}^{-3}\right), M_{a}$ the molar mass of air $\left(\mathrm{kg} \mathrm{mol}^{-1}\right), D=\frac{\rho_{a}}{M_{a}} \frac{e_{i}-e_{a}}{p}$ the molar vapour concentration gradient between the intercellular space and the air $\left(\mathrm{mol} \mathrm{m}^{-3}\right)$, and $C_{a}$ and $C_{i}$ the molar carbon dioxide concentration in the ambient air and in the stomata $\left(\mathrm{mol} \mathrm{m}^{-3}\right)$, respectively. The process of photosynthesis is described with the biochemical model of Farquhar et al. (1980). In this model, actual photosynthesis is the minimum of enzymelimited and electron-limited carboxylation, less dark respiration:

$A=\frac{\nu\left(C_{i}-\Gamma^{*}\right)}{C_{i}+\gamma}-R_{d}$

$v=V_{c m}$ and $\gamma=K_{c}\left(1+\frac{O}{K_{o}}\right)$ for Rubisco limited photosynthesis and $\nu=\frac{q I J_{m}}{4\left(I+2.1 J_{m}\right)}$ and $\gamma=2 \Gamma^{*}$ for photon limited photosynthesis, $V_{c m}$ is the maximum carboxylation capacity of Rubisco $\left(\mathrm{mol} \mathrm{m}^{-2} \mathrm{~s}^{-1}\right), \Gamma^{*}$ the compensation point for carbon dioxide in absence of dark respiration $\left(\mathrm{mol} \mathrm{m}^{-3}\right), O$ the 


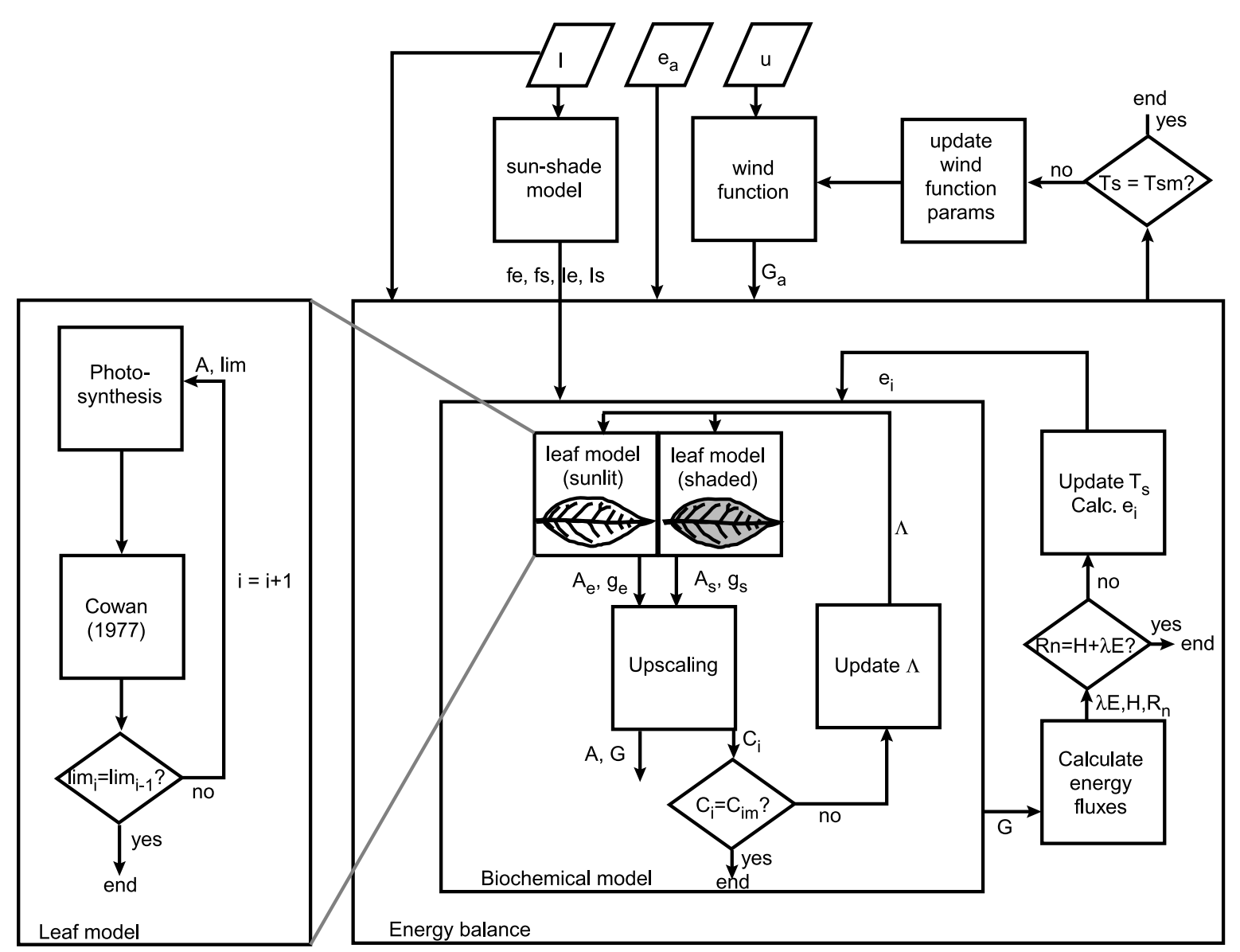

Fig. 1. Flow chart of the combined photosynthesis-transpiration model. The enlargement at the left represents the biochemical model at leaf level.

oxygen concentration $\left(\mathrm{mol} \mathrm{m}{ }^{-3}\right), K_{o}$ and $K_{c}$ the MichaelisMenten constants for carbon dioxide and oxygen $\left(\mathrm{mol} \mathrm{m}^{-3}\right)$, $R_{d}$ dark respiration $\left(\mathrm{mol} \mathrm{m}^{-2} \mathrm{~s}^{-1}\right), q$ the quantum yield efficiency, $J_{m}$ the maximum potential electron transport rate $\left(\mathrm{mol} \mathrm{m} \mathrm{m}^{-2} \mathrm{~s}^{-1}\right)$ and $I$ the irradiance by photosynthetically active radiation (PAR) $\left(\mathrm{mol} \mathrm{m}^{-2} \mathrm{~s}^{-1}\right)$.

Once values for the biochemical parameters are known, the diffusion equations (Eqs. 1 and 2) and the biochemical model (Eq. 3) form a set of three equations containing four unknowns $\left(A, E, g\right.$ and $C_{i}$ ). A fourth equation, describing the stomatal behaviour, is required to yield a unique solution. Cowan (1977) and Cowan and Farquhar (1977) suggested that stomata operate such as to minimize the evaporative cost of plant carbon gain. This condition is met if the marginal water cost of assimilation $\Lambda$, is constant with time:

$\frac{\delta E / \delta g}{\delta A / \delta g}=\Lambda=$ constant

This model does not explain how stomatal regulation works physiologically, but only describes the stomatal behaviour that yields the highest mean assimilation rate over a time pe- riod with variable environmental conditions, during which a certain positive amount of water evaporates. The parameter $\Lambda$ is a measure for the intrinsic water use (Lloyd and Farquhar, 1994). Low values of $\Lambda$ refer to more water efficient vegetation than high values. The advantage of this model for stomatal behaviour compared to empirical relations between stomatal conductance and humidity deficit, is that only one parameter, which has a conceptually clear meaning, is used. The model works best for the diurnal cycle, although it has also been applied to longer time periods, including dry conditions (Cowan, 1986). A problem with longer time scales and dry periods is that $\Lambda$ does not remain constant (Makela et al., 1996; Arneth et al., 2002), because of hydraulic limitation of transport of water (Tyree and Sperry, 1988; Jones, 1998; Mencuccini, 2003) and because stomata respond to abscisic acid transmitted by roots (Zhang and Davies, 1989).

With Eqs. (1) to (4), the variables $A, E, g$ and $C_{i}$ are uniquely defined. Solving Eqs. (1) to (4) results in a $C_{i}$ that is a function of the vapour gradient $D$ between the intercellular space and the air (Appendix A). The solution is different for 
the case in which assimilation is enzyme limited and for the case in which assimilation is electron limited. Because it is not known a-priori whether assimilation is enzyme or electron limited, $C_{i}$ is solved by iteration of Eqs. (A1) to (A3) and the biochemical model (Eq. 3).

Climate variables in this model are photosynthetically active radiation (PAR), vapour pressure deficit and carbon dioxide concentration. Biochemical parameters are maximum carboxylation capacity $V_{c m}$ and maximum electron transport $J_{m}$, quantum yield efficiency $q$, marginal cost of assimilation $\Lambda$ and Michaelis-Menten coefficients for the chemical reactions in the Calvin cycle.

The approach used to scale from leaf to canopy level (Appendix B) is similar to that of De Pury and Farquhar (1997). Lambert-Beer's equation is used to calculate the vertical distribution of light in the canopy, discriminating between indirect (diffuse) and direct light, which have different extinction coefficients. Because the experimental sites were located on steep slopes, a coordinate rotation was used to correct for the effect of topography on the extinction coefficients for direct light (Appendix B). The model calculates the exposed and shaded fraction of leaves $\left(f_{e}\right.$ and $\left.f_{s}\right)$, and the intensities of PAR on the exposed and shaded leaves $\left(I_{e}\right.$ and $\left.I_{s}\right)$, which are variable over the day. The fluxes and the surface conductance at canopy level are calculated by adding the contributions of the two fractions:

$V=L\left(f_{e} v_{e}+f_{s} v_{s}\right)$

where $V$ and $v$ refer to any of the variables $A, E$ and $g$ at canopy and leaf level, respectively, the index $e$ to exposed and $s$ to shaded, and $L$ is leaf area index. The effective internal carbon dioxide concentration for the canopy is:

$C_{i}=C_{a}-\frac{A}{G}$

where $A$ is canopy assimilation and $G$ the canopy-scale equivalent of $g$.

For the calculation of $E$ with Eq. (1), an estimate of the internal vapour pressure $e_{i}$ is needed, which cannot be measured directly. The intercellular vapour pressure is in equilibrium with leaf water potential and leaf temperature. Because air in stomata is always close to saturation, we assume that $e_{i}$ is the saturated vapour pressure $e_{s}$ at surface temperature $T_{S}$ :

$e_{i}=e_{s}\left(T_{s}\right)$

Surface temperature is solved from the energy balance. Neglecting soil heat flux and changes in heat storage, the energy balance is:

$R_{n}=H+\lambda E$

where $R_{n}$ is net radiation, $H$ sensible and $\lambda E$ latent heat flux (all in $\mathrm{W} \mathrm{m}^{-2}$ ). Latent heat flux is calculated by converting $E$ from units of $\mathrm{mol} \mathrm{m}^{-2} \mathrm{~s}^{-1}$ to $\mathrm{kg} \mathrm{m}^{-2} \mathrm{~s}^{-1}$ and multiplying by the latent heat of vaporisation of water, $\lambda$ $\left(=2.501-0.0024 T\left({ }^{\circ} \mathrm{C}\right) \mathrm{MJ} \mathrm{kg}^{-1}\right)$.

$\lambda E=1.6 \lambda \rho_{a} G \frac{M_{\mathrm{H}_{2} \mathrm{O}}}{M_{a}} \frac{e_{i}-e_{a}}{p}$

where $M_{\mathrm{H}_{2} \mathrm{O}}$ the molar mass of water $\left(\mathrm{kg} \mathrm{mol}^{-1}\right)$. Sensible heat flux is calculated as:

$H=\rho_{a} c_{p} G_{a}\left(T_{s}-T_{a}\right)$

where $G_{a}$ the aerodynamic conductance. Net radiation is calculated from incoming and outgoing shortwave and longwave radiation:

$R_{n}=(1-\alpha) R_{s i}+R_{l i}-R_{l o}$

where $R_{s i}, R_{l i}$ and $R_{l o}$ incoming shortwave, incoming longwave and outgoing longwave radiation, respectively, and $\alpha$ the reflection coefficient for shortwave radiation (albedo). Outgoing longwave radiation is calculated with StefanBoltzman's equation:

$R_{l o}=\varepsilon \sigma T_{S}^{4}$

where $\varepsilon=0.98$ the emissivity of the canopy and $\sigma$ StefanBoltzman constant $\left(=5.67 \times 10^{-8} \mathrm{~W} \mathrm{~m}^{-2} \mathrm{~K}^{-4}\right)$.

From the biochemical model (Eq. 1 to 4$), A, E, C_{i}$ and $g$ can be solved, provided that $e_{i}$ is known. Equation (5) is used to scale from leaf to canopy, and from the energy balance (Eqs. 7 to 12), $e_{i}, T_{l}, R_{l o}, R_{n}, H$ and $\lambda E$ can be solved, provided that $G$ and $G_{a}$ are known. Both sub-models should be solved simultaneously. An analytical solution is not possible due to the non-linearity of the interactions between the sub-models. For this reason, surface temperature is adjusted iteratively in order to force energy balance closure.

The aerodynamic conductance $G_{a}$ is calculated with a wind function:

$G_{a}=G_{a 0}+B u$

where $G_{a 0}$ a convective term, $u$ wind speed measured at the meteorological station $\left(\mathrm{m} \mathrm{s}^{-1}\right)$, and $B$ an empirical wind function. The terms $G_{a 0}$ and $B$ are calibrated by optimising calculated surface temperatures $T_{s}$ with measured ones. Because $T_{s}$ is measured only at the south plot, the parameters $G_{a 0}$ and $B$ of the south plot are also used at the other three plots.

\subsection{Site description}

The study was part of a broader project to study the effects of natural reforestation on the water balance and geomorphology of the river catchment of the Dragonja River in Mediterranean Slovenia (N45 $28^{\prime}$ E13 ${ }^{\circ} 46^{\prime}$, Fig. 2).

The Dragonja catchment is located within a $30 \mathrm{~km}$ wide band along the Adriatic coast of the peninsula of Istria with has a Sub-Mediterranean climate. The Julian Alps and up 


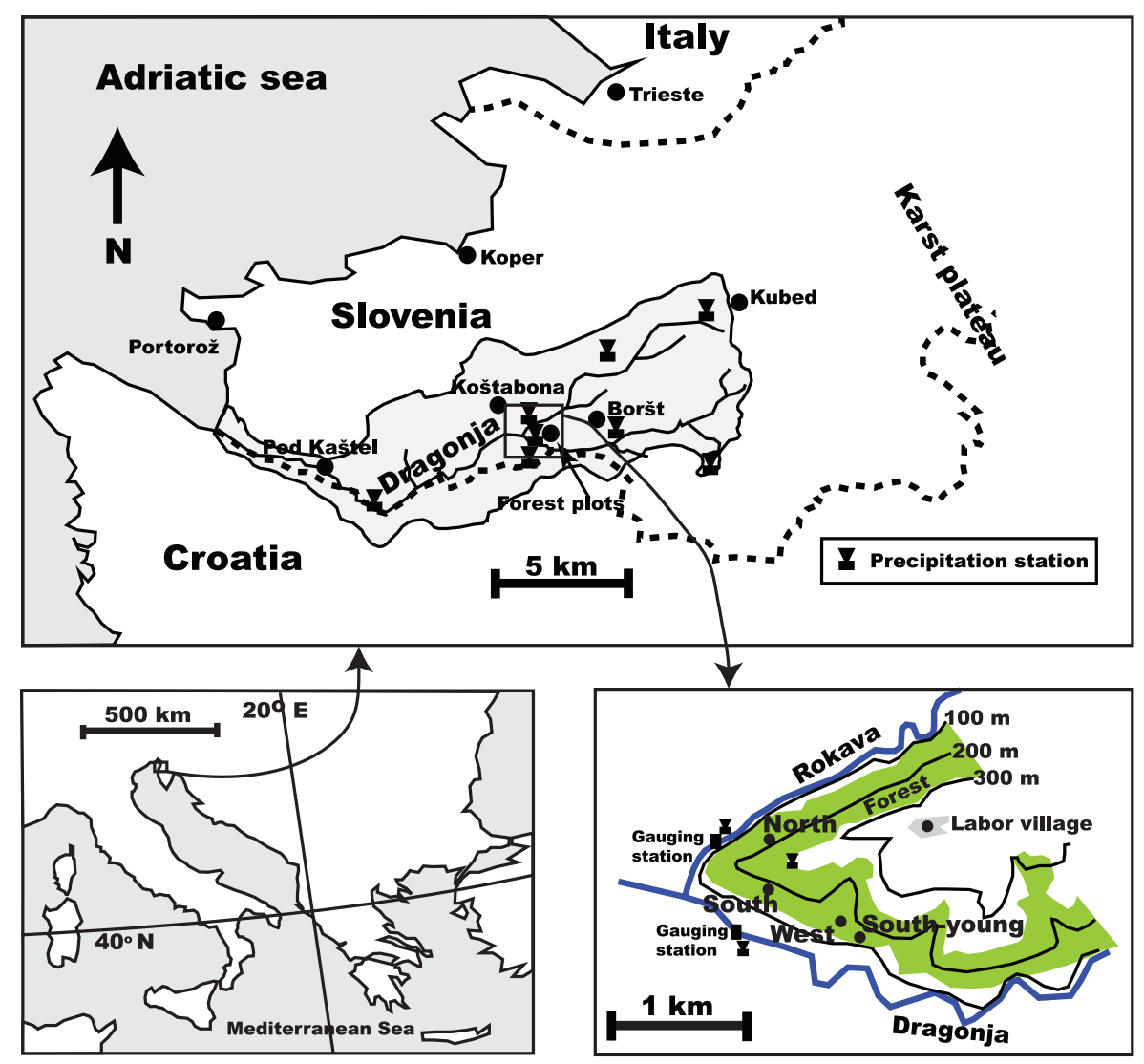

Fig. 2. Map showing the location of the four forest plots and meteorological stations.

to $1500 \mathrm{~m}$ high Karst plateaus form sharp orographic boundaries at the north and the east with a more continental climate, with lower temperatures and higher precipitation. The SubMediterranean climate is classified as Caf (mild winter, hot summer, no dry season) in the Köppen system. Mean annual precipitation varies from $1300 \mathrm{~mm}$ at the source to $1000 \mathrm{~mm}$ at the outlet of the Dragonja and is distributed evenly over the year.

The parent material in the Dragonja catchment is flysch: a sequence of calcareous shales and thin sandstone banks. In the upper part of the catchment, broad plateaus are intersected with narrow, steep river valleys of two contributing streams. In the lower part, the valley is broad and the plateaus narrow. The elevation ranges between 0 and $330 \mathrm{~m}$ above sea level. Soils in the whole catchment are Rendzina soils (Keesstra, 2006) and consist of clay loam (30 percent sand, 50 percent silt, 20 percent clay). Soil depth ranges from a few decimeters on the slopes to several meters of alluvial deposits in the valley.

Four experimental plots were selected in deciduous forests, which contrasted in aspect, local hydrological and climate conditions and vegetation composition (Fig. 2). The forests had developed with minimum human interference during the last 50 years. Both texture and chemical composition of the soils at the plots were similar. One plot was located on a north and one on a south facing slope (north and south plot), and one at the foot of a converging west facing slope (west plot) and one with younger forest on a diverging south facing slope (south-young plot).

Relative differences in water availability, light, temperature and vapour pressure deficit among the plots are presented schematically in Fig. 3. Two plots were predominantly sunlit and experience a high vapour pressure deficit, temperature and radiation input (south and south-young), and two plots predominantly shaded and experience a low vapour pressure deficit, temperature and radiation input (north and west). Two plots experience a high (north and south-young) and two plots a low (south and west) water availability. In this way, each of the four combinations of high and low vapour pressure deficit and high and low soil moisture content was present.

The plots not only contrasted in micro-environment, but also in species composition (Fig. 4), stem density and forest structure (Table 1). The dominant species were Carpinus betulus at the two shaded plots (north and west), and Quercus pubescens at the two exposed plots (south and south-young). 
Table 1. Characteristics of the four experimental forest plots in the Dragonja catchment.

\begin{tabular}{lcccc}
\hline & north & south & west & south-young \\
\hline elevation $(\mathrm{m})$ & 180 & 190 & 120 & 150 \\
slope & $30^{\circ}$ & $30^{\circ}$ & $30^{\circ}$ & $30^{\circ}$ \\
aspect & $330^{\circ}$ & $210^{\circ}$ & $270^{\circ}$ & $210^{\circ}$ \\
plot size $\left(\mathrm{m}^{2}\right)$ & 625 & 313 & 250 & 100 \\
soil depth $(\mathrm{m})$ & 1.0 & 1.0 & 1.0 & 0.8 \\
soil type & clay loam & clay loam & clay loam & clay loam \\
no of stems ha ${ }^{-1}\left(10^{3}\right)$ & 2.3 & 7.2 & 3.4 & 14.4 \\
average diameter $(\mathrm{cm})$ & 12.8 & 7.3 & 8.6 & 4.0 \\
average height $(\mathrm{m})$ & 16 & 8 & 14 & 4 \\
mid-season LAI & 4.0 & 5.2 & 4.5 & 2.7 \\
age (y) & $>100$ & $>100$ & $>100$ & 60 \\
management (1900) & wood gathering & cattle grazing & wood gathering & crop field \\
management (current) & wood gathering & wood gathering & wood gathering & wood gathering \\
\hline
\end{tabular}

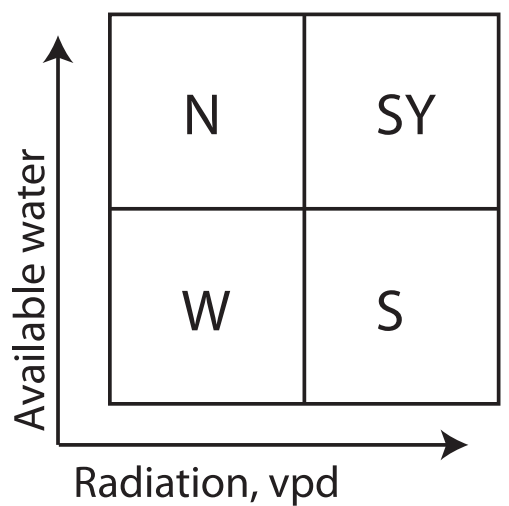

Fig. 3. Schematic representation of relative differences in vapour pressure deficit and soil water availability the four forest plots: north $(\mathrm{N})$, south (S), west (W) and south-young (SY).

Trees at the shaded plots were taller than at the sunlit plots. The forest at the south-young plot was younger, and pioneer vegetation was present (Juniperus communis).

\subsection{Measurements}

At each plot, vegetation and soil parameters, meteorological variables and the water balance were measured between May and September 2004. We selected only those data for which vegetation was not limited by water availability. The reason for doing so is that we are interested in the diurnal cycle during a period in which biochemical parameters remain constant, and water stress causes biochemical parameters to change in time (Lambers et al., 2000). Those temporal variations of biochemical parameters in a changing environment are the subject of a study we will publish separately.
Basic meteorological variables (wind speed, diffuse and direct incoming shortwave radiation and reflected shortwave radiation) were measured at a meteorological station $3 \mathrm{~km}$ east of the experimental plots. Parameters for the biochemical model at leaf level were derived from leaf chamber photosynthesis measurements carried out on two species at the south and the south-young plot, and leaf nitrogen content and ${ }^{13} \mathrm{C}$ isotope discrimination at all four plots.

Incoming and outgoing short wave and long wave radiation and net radiation were measured at one of the plots (south) with a CNR1 radiometer (Kipp and Zonen, Delft, Netherlands) mounted above the canopy. The temperature of the instrument itself was measured with a PT100 resistive temperature device. This setting provided accurate measurement of radiative temperature. In addition, radiative temperature was measured with a $4000.4 \mathrm{ZH}$ Everest radiometer (Everest Interscience, Inc.) Both instruments were pointed in NADIR. The radiative temperatures measured with the two instruments agreed very well, and only the data of the CNR1 radiometer were used in the analysis.

Temperature and relative humidity were measured at two $\mathrm{m}$ height with aspirated, shielded humicaps (HMP45AC, Vaisala Oyj, Finland), which were calibrated against a wet and dry bulb copper-constantan thermocouples (Vrije Universiteit Amsterdam) before and after the study. Mean daytime temperature during the growing season was $22.8^{\circ} \mathrm{C}$, $23.9^{\circ} \mathrm{C}, 21.4^{\circ} \mathrm{C}$ and $24.3^{\circ} \mathrm{C}$ for the north, south, west and south-young plot, respectively, and mean daytime vapour pressure deficit $11.0 \mathrm{hPa}, 13.3 \mathrm{hPa}, 9.6 \mathrm{hPa}$ and $14.2 \mathrm{hPa}$ for the same plots.

Light response curves of photosynthesis and transpiration of leaves of Quercus pubescens (13 leaves of 2 trees) and Fraxinus ornus (6 leaves of 2 trees) were measured using a broadleaf leaf chamber with portable light unit connected to an LCA3 gas analyser (ADC BioScientific Lt., UK) at the 

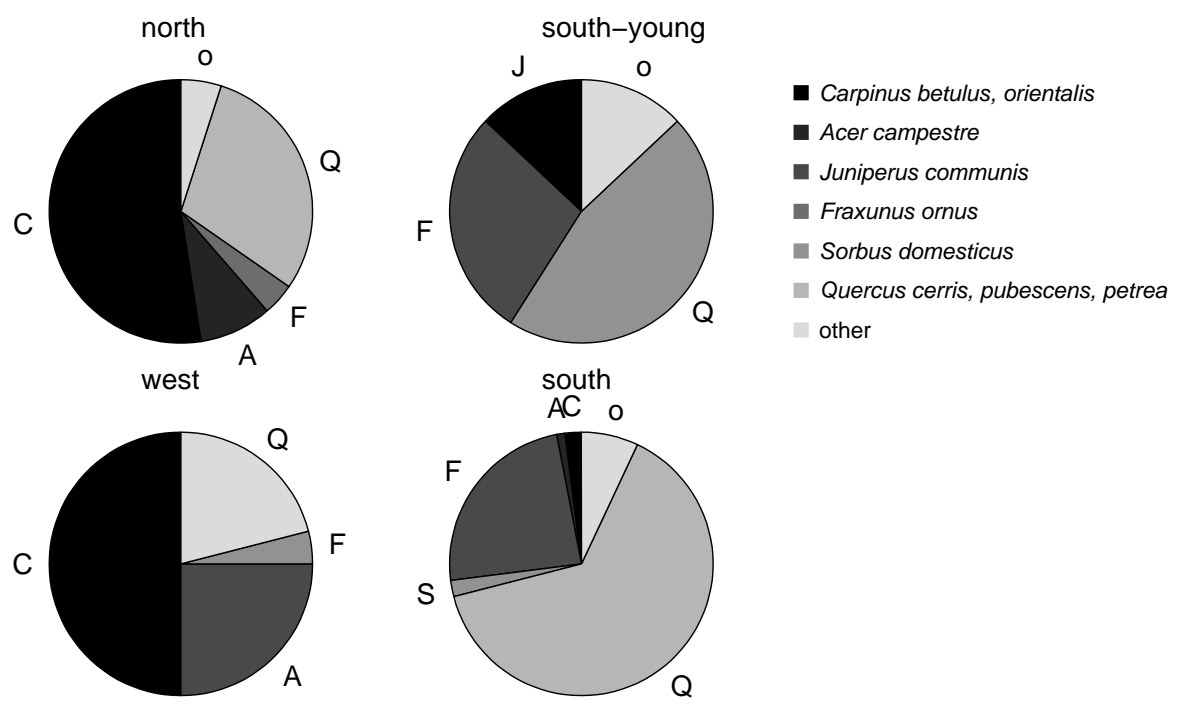

Fig. 4. Distribution of sap wood area over different species at the four forest plots.

south-young and the south plot between 14 and 21 July 2004. At the south-young plot, the trees were so small that measurements could be carried out at breast height. At the south plot, measurements were carried out on a scaffolding tower of $9 \mathrm{~m}$ height. The two species sampled are the most abundant species at the south and the south-young plot.

Leaf samples for analysis of carbon and nitrogen content and ${ }^{13} \mathrm{C}$ isotope discrimination were collected by a professional tree climber at the start (a few weeks after bud break) and the end (four weeks before the onset of senescence) of the growing season at all four plots. The total number of leaf samples was 83 (15 at the north, 31 at the south, 16 at the west and 21 at the south-young plot). One third of the samples was collected between 5 May and 8 June 2004, and two third between 8 and 10 September 2004. Each sample consisted of 4 to 15 leaves of different size from neighbouring branches of a tree. The number of samples of a species was chosen such that it approximated the relative contribution to the total sapwood area of that species at the plot. Species which contributed less than 5 percent to the total sapwood area were not sampled. At all plots, the sampled species represented over 85 percent of the sapwood area. Leaves were collected both high in the canopy (predominantly sunlit) and low in the canopy (predominantly shaded). Samples were classified by plot, species, sunlit or shaded, and young or old leaves.

The leaves were air dried, oven dried at $50^{\circ} \mathrm{C}$, minced in a mincing machine and grounded in centrifugal ball mill. Carbon and nitrogen content (percentage by weight) and discrimination of ${ }^{13} \mathrm{C}$ were determined using an elemental CHNO-analyzer Flash EA 1112 (Finnegan MAT, Bremen, Germany).
The ${ }^{13} \mathrm{C}$ discrimination against ambient air was calculated as (Farquhar and Richards, 1984):

$$
\Delta^{13} C_{l}=\frac{\delta^{13} C_{a}-\delta^{13} C_{l}}{1+\Delta^{13} C_{l}}
$$

where $\delta^{13} C$ the isotope ratio per mil compared to the PDB standard, subscript $a$ and $l$ indicate air and leaf, respectively, and $\delta^{13} C_{a}=-8 \mathrm{ppm}$. The long-term internal carbon dioxide concentration was calculated as (Farquhar et al., 1989):

$$
\frac{C_{i}}{C_{a}}=\frac{\Delta^{13} C_{l}-c_{1}}{c_{2}-c_{1}}
$$

where $c_{1}=4.4$ per mil the discrimination by diffusion in air and $c_{2}=27$ per mil the discrimination by Rubisco.

The leaf samples were used to calculate effective values for leaf nitrogen content and ${ }^{13} \mathrm{C}$ isotope discrimination for each plot. First, a Kolmogorov-Smirnov test showed that the measurements of leaf nitrogen and ${ }^{13} \mathrm{C}$ within each plot had normal distributions, and a Levene test showed the variances within the plots were not different from each other. Next, the estimated mean values $\hat{m}$ and variances $\hat{s}^{2}$ for each plot were calculated as:

$$
\begin{aligned}
& \hat{m}=\sum_{n_{s}} F_{i} m \\
& \hat{s}^{2}=\sum_{n_{s}} F_{i}^{2} \hat{s}_{i}^{2}
\end{aligned}
$$

where $F_{i}$ the contribution of species $i$ to total sapwood area, and $n_{s}$ the number of sampled trees of species $i$. A 95\% confidence interval for the mean was calculated as:

$$
m=\hat{m} \pm s_{0.95} \sqrt{\frac{\hat{s}^{2}}{n_{p}}}
$$


where $s_{0.95}$ the Student-t statistic for $p=0.95$ and $n_{p}$ the number of samples at each plot.

The parameters for the model of Farquhar and internal carbon dioxide concentration for each plot were derived in the following way. First, maximum carboxylation capacity and electron transport capacity for each plot were calculated by fitting the Farquhar model to the leaf chamber photosynthesis measurements. Next, a linear relationship between maximum carboxylation capacity and leaf nitrogen content was fitted for the leaves for which measurements of both leaf nitrogen content and maximum carboxylation capacity were available. Finally, this linear relationship was used to derive values for the maximum carboxylation capacity at all four plots from measurements of leaf nitrogen content. Leaf nitrogen content did not change significantly between the start and the end of the season, whereas the light response curves changed and the parameters $V_{c m}$ and $J_{m}$ dropped after the onset of drought (not shown).

The average values of internal carbon dioxide concentration $\bar{C}_{i}$ from the isotope analysis were used to calibrate the model parameter $\Lambda$ for each plot, by minimising the absolute difference between measured and calculated internal carbon dioxide concentration. Modelled internal carbon dioxide concentration changes during the day. An average was calculated by weighing $C_{i}$ with the instantaneous rate of photosynthesis (Farquhar et al., 1982):

$\bar{C}_{i}=\int \frac{A(t) C_{i}(t)}{\bar{A}} d t$

Temperature, relative humidity, vertical profiles of soil moisture content and sap flux density were measured continuously at each plot, and data stored at 30-min intervals. Precipitation was measured at 3 stations within $500 \mathrm{~m}$ of the forest plots. Transpiration was calculated from sap flux density measurements with the method of Granier (1987). At each plot, 12 sensors were installed in 6 trees $(2$ sensors per tree). The trees were selected such that they best represented the distribution of species and stem diameters (Fig. 4). From each of the three most abundant species at each plot, at least one tree was sampled. Fraxinus ornus was sampled at all four plots because it was present at all plots, and either Quercus pubescens or Quercus cerris was sampled at each plot. Both ring porous (Quercus and Fraxinus ornus) and diffuse porous species (Carpinus betulus, Juniperus communis and Acer campestre) were sampled.

Effective mean sap flux density and a 95\% confidence interval were calculated from the individual sensors weighed by the contribution of each species to the total sapwood area, in the same way as for leaf nitrogen (Eq. 16 to 18). Latent heat flux, $\lambda E\left(\mathrm{~W} \mathrm{~m}^{-2}\right)$, was calculated by multiplying sap flux density by the area of sapwood per unit forest floor $f_{A}$ and by the latent heat of vaporization of water $\lambda$ $\left(2.5 \mathrm{MJ} \mathrm{kg}^{-1}\right)$ :

$\lambda E=\lambda f_{A} m$
The area of sapwood per unit forest floor, $f_{A}$, was calculated in the following way. Because the sensors had a length of $20 \mathrm{~mm}$ and were inserted in heat-conducting material, it was assumed that the measured sap flux density is the effective sap flux density of the outer $20 \mathrm{~mm}$ of the stem. If sapwood area extends deeper than $20 \mathrm{~mm}$ into the stem, then the sap flux measurements are underestimates. For this reason, the actual sapwood area was inferred from microscopic analysis of tree cores taken perpendicular to the tree rings of all sampled trees at the end of the growing season of 2004. A film of approximately $0.1 \mathrm{~mm}$ thickness was planed off the tree cores with a razor blade and examined visually under a microscope for the presence of active xylem vessels. The majority of xylem vessels were present in the outer $20 \mathrm{~mm}$, and few extended up to $40 \mathrm{~mm}$ depth. The number of sampled trees (24) was too small to establish a relationship between sapwood area, species and plot. Because only 10 to $30 \%$ of active xylem vessels were present at depths greater than $20 \mathrm{~mm}$, we used a value of $25 \mathrm{~mm} \pm 10 \%$ for the sapwood depths for all trees at all plots. The total sapwood area per unit forest floor was calculated by measuring the diameters of all trees in each plot.

It is noteworthy that leaf nitrogen content and isotope discrimination were calculated as averages from leaf samples weighed with the relative contribution of species to total sapwood area (Eq. 16), whereas latent heat was calculated by multiplying sap flux density with the absolute values of sapwood area (Eq. 20). Latent heat flux is therefore sensitive to errors in sapwood area, and leaf nitrogen content and isotope discrimination only to errors in the relative contribution of each species.

The sun-shade model for light interception was validated using PAR measurements along horizontal transects at the forest floor of the north and the south plot, and along vertical transects at the south plot, at different weather conditions, times of the day and days of the year. PAR was measured with a ceptometer (Degacon Instruments Inc.) with 80 sensors covering a length of $80 \mathrm{~cm}$. Each measurement point was the average of 430 measurements taken at regular intervals along a transect of $25 \mathrm{~m}$, i.e. the average of $430 \times 80=3 \times 10^{4}$ individual PAR measurements. Measurements along the vertical transect consisted of 10 measurements with the ceptometer at each $1 \mathrm{~m}$ interval, i.e. 800 individual PAR measurements. Measurements were taken between 6 AM and 6 PM during the entire field campaign. Diffuse and direct light were separately measured at the meteorologic station, and a model was used which accounts for the extinction of both components as a function of azimuth, leaf area index, leaf angle distribution, and slope of the surface. This model is described in Appendix B. Leaf area index $L$ was derived from PAR measurements on completely overcast days. 
Table 2. A-priori parameter values for the biochemical model. (Farquhar et al., 1980)

\begin{tabular}{lllll}
\hline$K_{c}\left(\mathrm{mmolm}^{-3}\right)$ & $K_{o}$ (mbar) & $O$ (mbar) & $\Gamma^{*}(\mathrm{mmolm}-3)$ & $J_{m} / V_{c m}$ \\
18.7 & 330 & 210 & 1.22 & 2.5 \\
\hline
\end{tabular}

Table 3. Fitted values of maximum carboxylation capacity $V_{c m}$, dark respiration rate $R_{d}$ and quantum yield efficiency $q$ with 0.95 -confidence intervals, fitted for measurements on 13 leaves of Quercus pubescens and 6 leaves of Fraxinus ornus at the south and the south-young plot between 14 and 21 July 2004.

\begin{tabular}{llll}
\hline & $V_{c m}\left(\mu \mathrm{molm}^{-2} \mathrm{~s}^{-1}\right)$ & $R_{d}\left(\mu \mathrm{molm}^{-2} \mathrm{~s}^{-1}\right)$ & $q$ \\
\hline Quercus pubescens & $54 \pm 9$ & $1.0 \pm 0.2$ & $0.46 \pm 0.15$ \\
Fraxinus ornus & $44 \pm 7$ & $1.1 \pm 0.0$ & $0.39 \pm 0.09$ \\
\hline
\end{tabular}

\section{Results}

In this section we present the derivation of the parameters for the biochemical model at leaf level from leaf chamber photosynthesis measurements and leaf samples, the validation of the sun-shade model, the model predictions of diurnal cycles of the fluxes. The discussion section is dedicated to a sensitivity analysis of the model.

\subsection{Biochemical model}

Figure 5 shows leaf chamber photosynthesis measurements used for parametrization of the biochemical model, and model predictions (solid lines). The upper panels show net assimilation as a function of photosynthetically active radiation (PAR), the lower panels $C_{i} / C_{a}$ versus PAR. The parameters $V_{c m}, R_{d}$ and $q$ of the photosynthesis model were fitted (Table 3) using these data, whereas a-priori values were used for other parameters (Table 2). The measurements were carried out at similar vapour pressure deficit $(10 \mathrm{hPa}$, controlled $)$ and temperature $\left(28 \pm 2{ }^{\circ} \mathrm{C}\right.$, not controlled).

The measured values of maximum photosynthesis rate of Quercus pubescens agree with measurements of Damesin and Rambal (1995), who found values of 10.0 to $16.5 \mu \mathrm{mol} \mathrm{m}^{-2} \mathrm{~s}^{-1}$ in a Mediterranean climate. If the hypothesis of Cowan (1977) holds, then $C_{i}$ should be independent of PAR. However, Fig. 5 shows a sharp increase of $C_{i} / C_{a}$ when PAR decreases to low values $\left(C_{a}\right.$ remained constant during these measurements). This is either caused by a minimum stomatal conductance that prevents the stomata to fully close, or by the fact that the time interval of 2 min between the measurements was too short for the stomata to reach an equilibrium. The first possibility implies that the model of Cowan (1977) is incomplete. The solid line in Fig. 5 was derived by assuming a relation between assimilation and stomatal conductance as proposed by Leuning (1995). In the analysis that follow the model of Cowan (1977) is used, because its parameter $\Lambda$ has a conceptually clear meaning.
The values for $V_{c m}$ for the two sampled species (Table 3) were used to fit the linear relationship between leaf nitrogen content and $V_{c m}$. Unfortunately, a direct translation from leaf nitrogen content to photosynthetic capacity is not possible, because leaf nitrogen content measurement were based on samples of multiple leaves, whereas $V_{c m}$ was calculated for individual leaves. Because of limited access to the canopy, leaf photosynthesis could not be measured for all species and not always for the same leaves as leaf photosynthesis. Ideally, data of all species should be used, and the relationship evaluated per species. Correlating leaf nitrogen content and photosynthetic capacity is a simplification, because the effects of leaf thickness and density are not considered. In spite of these simplifications, there is evidence that leaf nitrogen content is positively related to photosynthetic capacity and maximum photosynthesis, even across different genotypes (Reich et al., 1999). Niinemets (1999) found a linear positive relationship between photosynthetic capacity (calculated by inverting the model of Farquhar) and leaf nitrogen content per unit dry mass among a large number of C3 species on earth. Figure 6 shows leaf nitrogen versus $V_{c m}$ for the two sampled species at the south and the south-young plot, with 0.95 confidence intervals for both nitrogen content and $V_{c m}$. We adopt a linear relation of Field and Mooney (1986) to relate $V_{c m}$ to nitrogen content:

$V_{c m}=x\left(N-N_{0}\right)$

where $N_{0}$ the residual leaf nitrogen content $\left(=25 \mathrm{mmol} \mathrm{m}^{-2}\right.$ or $0.5 \%), N$ leaf nitrogen content $\left(\mathrm{mmol} \mathrm{m}^{-2}\right.$ or $0.5 \%$ or $\left.\mathrm{g}(100 \mathrm{~g} \mathrm{DM})^{-1}\right)$, and $x$ an empirical coefficient. We fitted $x$ for the two measurement points (solid line in Fig. 6), acknowledging the ambiguousness to use this relationship based on two data points for all plots. Our data agree with literature data (dots in Fig. 6), calculated (using otherwise equal parameter values) from values of maximum photosynthesis by Reich et al. (1999) for different vegetation types in North and South America. Our data are in the same order of magnitude and the relation between leaf nitrogen content and photosynthetic capacity is similar. 

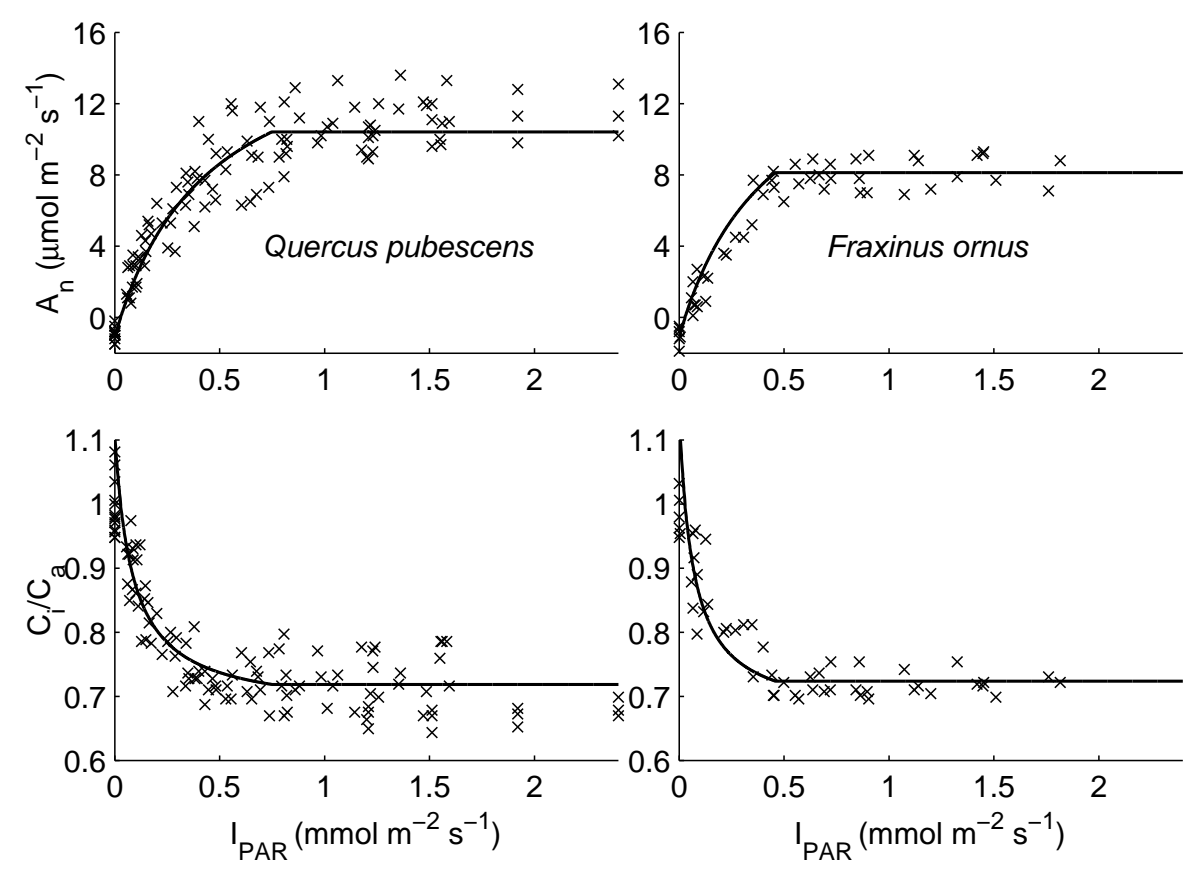

Fig. 5. Rates of net photosynthesis ( $\mu \mathrm{mol} \mathrm{m} \mathrm{m}^{-2} \mathrm{~s}^{-1}$ ) (upper panels), and $C_{i} / C_{s}$ versus intensity of photosynthetically active radiation PAR $\left(\mathrm{mmol} \mathrm{m} \mathrm{s}^{-2} \mathrm{~s}^{-1}\right.$ ) (lower panels) for Quercus pubescens and Fraxinus ornus. Measurements were carried out at the south and the south-young plot between 14 and 21 July 2004. The solid line is a prediction of the fitted biochemical model. For the lines in the lower panels, the model of Leuning (1995) was used.

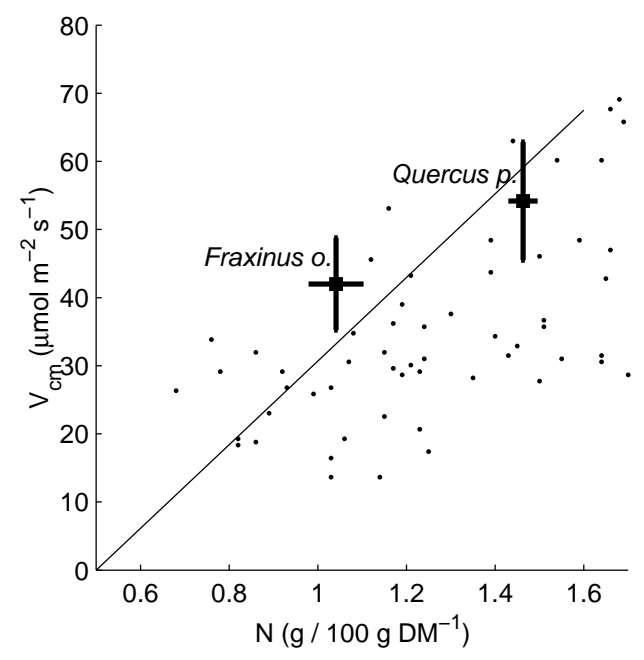

Fig. 6. Mean maximum carboxylation capacity $V_{c m}$, with $0.95-$ confidence intervals for Quercus pubescens and Fraxinus ornus, versus mean leaf nitrogen with 0.95 -confidence intervals, measured at the south and the south-young plot, and a linear regression line through the two data points, forced through $V_{c m}(0.5)=0$. Dots refer measurements by Reich et al. (1999) between $\mathrm{N}=0$ and $\mathrm{N}=1.7 \mathrm{~g}$ $\left(100 \mathrm{~g} \mathrm{DM}^{-1}\right.$, and were calculated with Eq. (3) from light saturated photosynthesis, assuming $C_{i}=0.7 C_{a}$ and using the constants of Table 2 and a quantum yield efficiency $q$ of 0.45 .
Table 4 shows the biochemical parameters as derived from the leaf sample analysis and leaf photosynthesis measurements, and leaf area index for the four plots. For $R_{d}$ and $q$, we used equal values for all plots. Differences in nitrogen content between sunlit and shaded leaves were not significant, perhaps due to the open structure of the canopy. It is remarkable that the two plots with the lowest vapour pressure deficit (north and west) have higher carboxylation capacity $V_{c m}$ than the two plots with the highest vapour pressure deficit (south and south-young), and that the two plots with the lowest soil moisture content (south and west) have a higher intrinsic water use efficiency (lower $\Lambda$ ) than the two plots with a higher soil moisture content. This topic will be discussed in detail in a separate study which focusses on the relation between climate and biochemical parameters.

\subsection{Sun-shade model}

Figure 7 shows the modelled versus the measured fraction of direct light that reaches the forest floor $I / I_{0}$ at the north and the south plot. The model prediction is reasonable for the south plot $\left(r^{2}=0.77\right)$, and poor for the north plot $\left(r^{2}=0.31\right)$, which can be attributed to the high spatial variability of sunfleck distribution at the north plot due to the heterogeneous structure of the forest. The values in the circle correspond to low light conditions in the late afternoon. Figure 8 shows 
Table 4. Mean values of leaf nitrogen concentration $[\mathrm{N}]$ and ${ }^{13} \mathrm{C}$ isotope discrimination with $95 \%$ confidence intervals, maximum carboxylation capacity $V_{c m}$, dark respiration $R_{d}$, marginal cost of assimilation $\Lambda$, quantum yield efficiency $q$, and leaf area index $L$ at the north, south, west and south-young plot. $V_{c m}$ was derived from leaf nitrogen concentration and leaf chamber measurements, $\Lambda$ from ${ }^{13} \mathrm{C}$ isotope discrimination, $q$ and $R_{d}$ from leaf chamber measurements and $L$ from PAR measurements.

\begin{tabular}{lllll}
\hline & north & south & west & south-young \\
\hline$[N]\left(\mathrm{g} 100 \mathrm{~g}^{-1}\right)$ & $1.61 \pm 0.08$ & $1.33 \pm 0.03$ & $1.74 \pm 0.16$ & $1.34 \pm 0.04$ \\
$\Delta{ }^{13} \mathrm{C}(\mathrm{ppm})$ & $21.20 \pm 0.24$ & $19.95 \pm 0.31$ & $19.76 \pm 0.21$ & $20.73 \pm 0.22$ \\
$V_{c m}\left(\mu \mathrm{mol} \mathrm{m}^{-2} \mathrm{~s}^{-1}\right)$ & 68 & 51 & 70 & 52 \\
$\Lambda$ & 1233 & 622 & 507 & 1030 \\
$R_{d}\left(\mu \mathrm{mol} \mathrm{m}^{-2} \mathrm{~s}^{-1}\right)$ & 1.0 & 1.0 & 1.0 & 1.0 \\
$q$ & 0.45 & 0.45 & 0.45 & 0.45 \\
$L$ & 3.9 & 4.4 & 4.2 & 2.5 \\
\hline
\end{tabular}

vertical profiles of measured (x) and modelled (line) light distribution in the canopy at the south plot, measured at different times of the day and for different weather conditions. The depth is in units of leaf area index, assuming a homogeneous leaf distribution over depth. From left to right and from top to bottom, the fraction of diffuse ambient irradiance increases from 13 to $100 \%$. The curves are similar in shape, and the model performs well in all conditions except for low solar angles and low light intensity (lower left and lower middle panel). Although the shape of the curves are similar, large differences exist in the irradiance on sunlit and shaded leaves depending on light conditions and time of the day. The insets show calculated values for the fractions of sunlit (open boxes) and shaded (shaded boxes) leaves, and the mean intensities of PAR on sunlit and shaded leaves. With increasing fraction of indirect radiation, the difference in irradiance between sunlit and shaded leaves decreases.

\subsection{Diurnal cycle of assimilation and latent heat}

Figure 9 shows the mean diurnal cycles of $A, \lambda E$ and $G_{s}$ for all 20 clear days between 29 May and 8 July 2004. During this period, the time of sunrise and sunset shifted by approximately $14 \mathrm{~min}$. Because this is smaller than the time resolution of the data $(30 \mathrm{~min})$, no correction was made for this. The lines are model predictions, the bars 0.95 confidence intervals for latent heat flux estimated from sap flux measurements (from now on referred to as measured latent heat), and surface conductance calculated from measured latent heat using the inverse Penman-Monteith equation.

The diurnal cycles of assimilation show some typical features which can be explained from biochemical properties and environmental conditions. The increase of assimilation in the morning and the decrease in the evening are slower at the north and the west than at the south and the south-young plot. This can be attributed to the lower fraction of sunlit leaves at the north and the west plot than at the south and the south-young plot, and consequently a greater contribution of leaves that assimilate at a light limited rate, even late in the

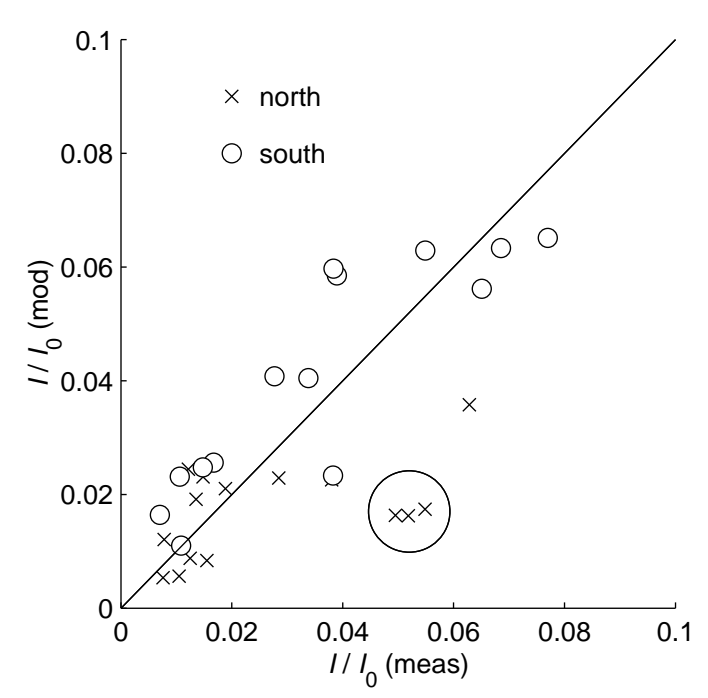

Fig. 7. Modelled versus measured fraction of ambient PAR that reaches the forest floor, for different weather conditions and different times of the day (6 to $19 \mathrm{~h}$ ) at the north and the south plot, for different days between May and September 2004. The values in the circle refer to low-light conditions in the late afternoon.

morning. Although assimilation reaches its peak later at the north and the west plot than at the south and the south-young plot, the peak values are higher due to a higher value of maximum carboxylation capacity $V_{c m}$.

The modelled diurnal cycles of latent heat closely match the measured latent heat. This is remarkable, because the measured latent heat was not used to calibrate any model parameter. The biochemical parameters $V_{c m}$ (the maximum carboxylation rate) and $\Lambda$ (the marginal cost of assimilation) affect latent heat flux in the following way. The north plot has the highest latent heat flux, because it has both a relatively high $V_{c m}$ and a relatively high $\Lambda$, i.e. a high photosynthetic capacity and a high marginal cost of assimilation. The west plot also has a relatively high $V_{c m}$, but a low $\Lambda$, 

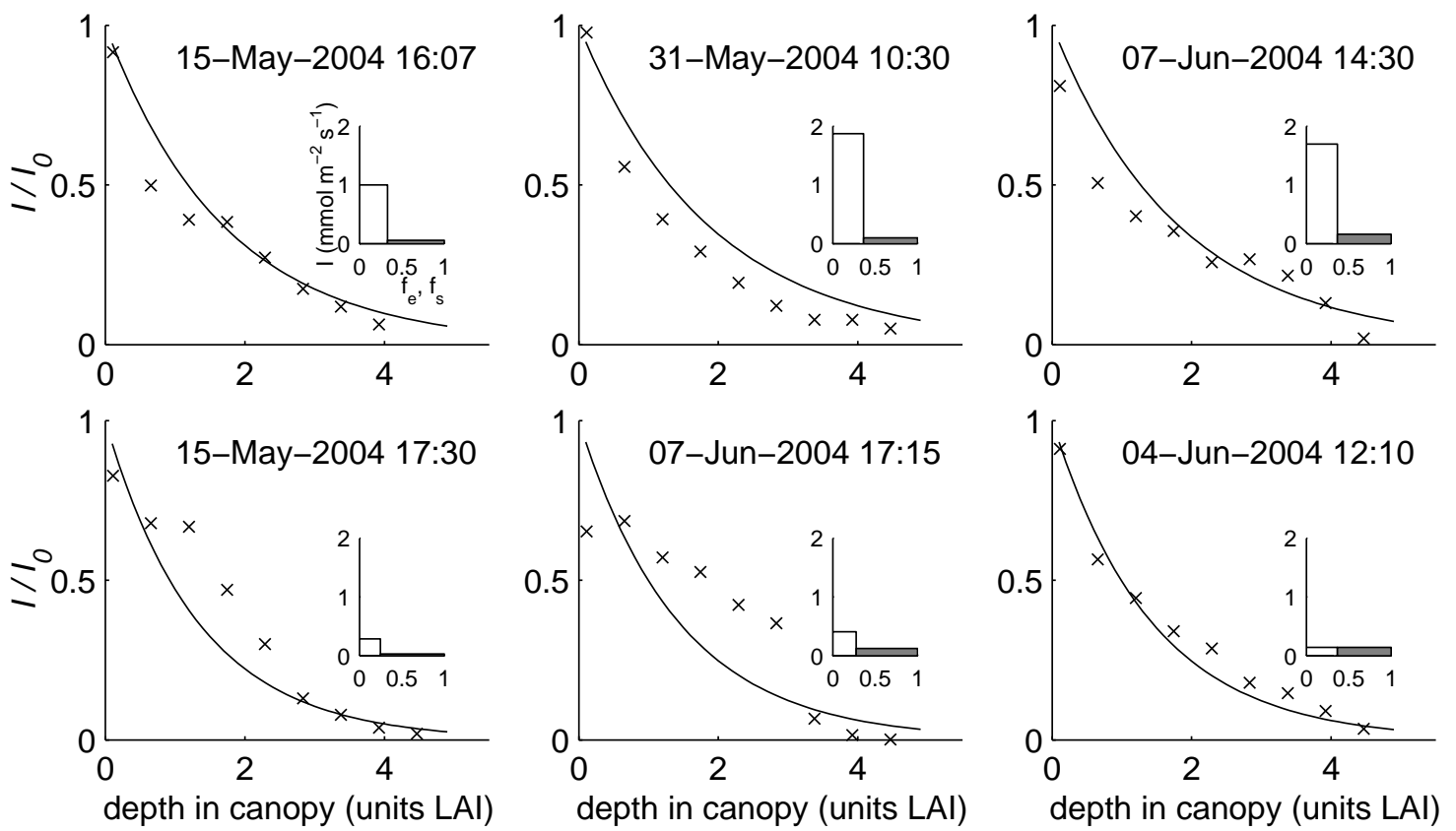

Fig. 8. Measured (x) and modelled (lines) vertical profiles of light intensity relative to ambient light $\left(I / I_{0}\right)$ for different weather conditions at the south plot on different days in May and June 2004. The insets indicate the difference between sunlit and shaded leaves: the open boxes refer to the sunlit fraction, the shaded boxes to the shaded fraction. The width of the boxes denotes the size of the fraction, and the height the intensity of PAR. From left to right and from top to bottom, the fraction of diffuse ambient irradiance increases from 13 to $100 \%$.

and therefore a lower latent heat flux than the north plot. The south and the south-young plot both have a relatively low $V_{c m}$, but the south-young plot has a higher $\Lambda$ and therefore a higher latent heat flux than the south plot.

The model accurately reproduces the diurnal cycles of surface conductance derived from the inverse Penman-Monteith equation. The north plot does not show afternoon stomatal closure, whereas the other three plots show a typical pattern of stomatal closure in the late morning and afternoon. This can be explained by the combined effects of vapour pressure deficit and the parameter $\Lambda$. Low values of $\Lambda$ (low marginal cost of assimilation) indicate early stomatal closure in response to vapour pressure deficit, whereas high values of $\Lambda$ indicate that stomata remain open relatively long. The values for $\Lambda$ are lower at the two plots with low water availability (south and west plot) than at the two plots with high water availability (north and south-young plot). Whether afternoon stomatal closure occurs is then indicated by the schematic representation of the plots in Fig. 3. At the north plot, stomata remain open because both $\Lambda$ is high and vapour pressure deficit low, whereas at all other plots, $\Lambda$ is low, stomatal deficits are high, or both. At south plot, $\Lambda$ is low and vapour pressure deficit high, at the west plot, $\Lambda$ is low, and at the south-young plot, vapour pressure deficit high. For all four plots, the modelled diurnal cycles agree with those derived from the inverse Penman-Monteith equation, which shows that measurements of leaf biochemistry and climate conditions together can be used successfully to reproduce the diurnal cycles of stomatal conductance, and to distinguish between the effects of biochemistry and climate.

In Fig. 10, the data are presented in a different way. This figure shows modelled versus measured latent heat flux for all half-hourly data between 29 May and 8 July 2004. The solid lines are 1:1 lines. For all plots, the squared correlation coefficients are above 0.90 . Latent heat flux at the north plot is slightly underestimated, and maximum latent heat flux at the south and south-young plot overestimated. The significance of this difference between measured and modelled latent heat flux is discussed in the next section using an error propagation analysis of the model. The relationship between modelled and measured latent heat flux is slightly convex, especially at the north and south slope. A closer look at the diurnal cycles shows that this effect is caused by the fact that sap flux continues for some time after sunset, and most likely lags behind latent heat flux in the afternoon. This aspect is discussed in the next section as well.

The model also predicts surface temperature. Radiative temperature was used for measured surface temperature. Modelled surface temperature is not independent of the measurements, because radiative temperature was also used to fit aerodynamic conductance at the south plot. Figure 11 shows for 27 June 2004, the measured and modelled 

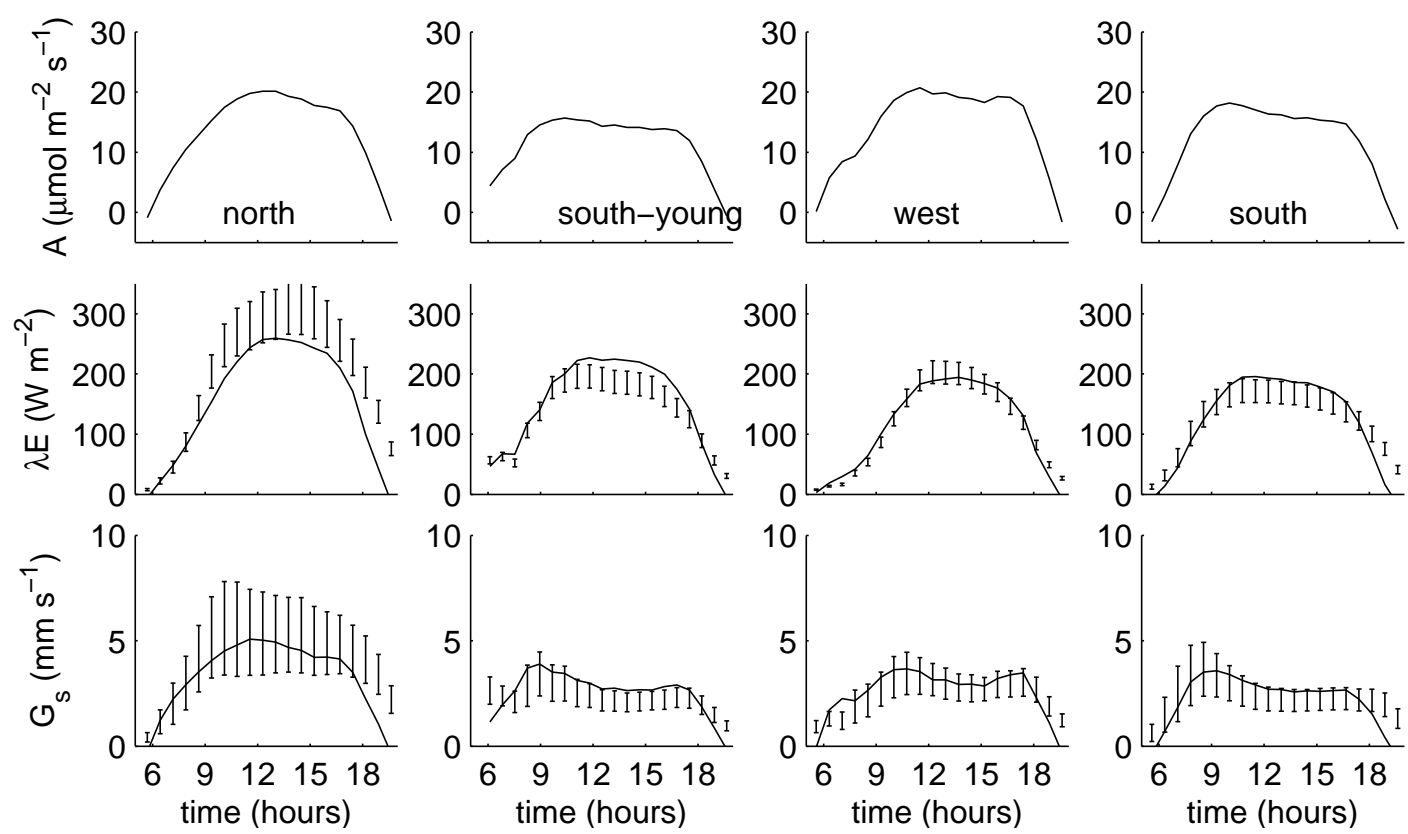

Fig. 9. Modelled rates of net photosynthesis $\left(\mu \mathrm{mol} \mathrm{m}{ }^{-2} \mathrm{~s}^{-1}\right)$, latent heat flux $\lambda E\left(\mathrm{~W} \mathrm{~m}^{-2}\right)$, and surface conductance $G_{S}\left(\mathrm{~mm} \mathrm{~s}{ }^{-1}\right)$ at the north, south, west and south-young plot for 20 clear days between 29 May and 8 July 2004. Lines are model predictions, and bars latent heat flux and surface conductance derived from independent sap flux measurements, and $95 \%$ confidence intervals, derived from measurements of 12 sap flux sensors per plot. Bars for surface conductance were derived by inverting the Penman-Monteith equation, using the sap-flux based estimates of latent heat flux.
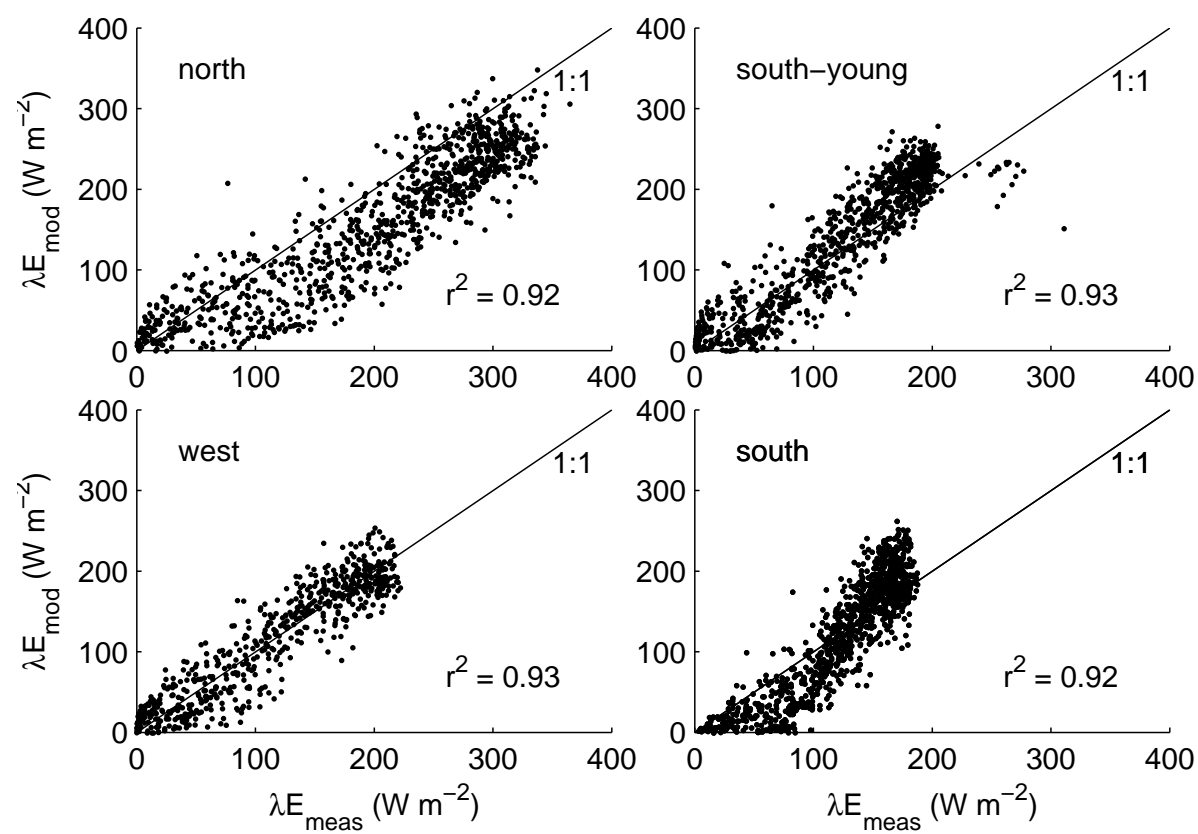

Fig. 10. Modelled versus sap-flux based latent heat flux at the north, south, west and south-young plot for half hourly data between 29 May and 8 July 2004. 
Table 5. Sensitivity of assimilation $A$ and latent heat $\lambda E$ to parameter or variable $x$ with standard deviation $\sigma_{x}$, calculated with Eq. (22). Standard deviation are also expressed as percentage of the mean values of assimilation and latent heat.

\begin{tabular}{llllll}
\hline$x$ & $\sigma_{x}$ & $\begin{array}{l}\sigma_{A} \\
\mu \mathrm{molm}^{-2} \mathrm{~s}^{-1}\end{array}$ & $\%$ & $\begin{array}{l}\sigma_{\lambda E} \\
\mathrm{Wm}^{-2}\end{array}$ & $\%$ \\
\hline$D$ & $3 \mathrm{hPa}$ & 0.30 & 5 & 4.0 & 5 \\
$V_{c m}$ & $10 \mu \mathrm{mol} \mathrm{m}^{-2} \mathrm{~s}^{-1}$ & 0.72 & 12 & 7.2 & 10 \\
$\Lambda$ & 100 & 0.27 & 4 & 5.8 & 8 \\
$L$ & 0.5 & 0.64 & 11 & 6.5 & 9 \\
\hline total & & 1.05 & 13 & 12 & 11 \\
\hline
\end{tabular}

difference between surface temperature and air temperature at the south plot (left panel), and the modelled temperature difference versus the measured temperature difference for all half hourly values between 19 May and 8 July 2004 (right panel). The correlation between modelled and measured surface temperature is lower than that for latent heat. This is a minor problem, because $T_{s}-T_{a}$ is relatively small compared to the diurnal cycle of $T_{a}$, and the model prediction of latent heat is not very sensitive to errors in $T_{s}-T_{a}$. The difference between the model and measurements could be related to a hot-spot effect in the radiative temperature measurements.

\section{Discussion}

The agreement between modelled and measured fluxes depends on the accuracy of four components: (1) measurements used for validation, (2) input variables, (3) parameter values and (4) the model description itself.

The uncertainty in the measurements for validation includes the variation of sap flux density measurements among sensors and the sapwood-surface area ratio. An additional error is that we ignored the time lag that exists between transpiration and sap flux due to storage of water in stems (Schulze et al., 1985). The data indicate that indeed for some time after sunset, sap flow continues. However, there is no reason why storage in stems and the time lag would be equal for all four plots (tree heights vary from $3 \mathrm{~m}$ at the south-young plot to $18 \mathrm{~m}$ at the north plot). To account for the time lag requires at least four additional parameters to be estimated (one for each plot). To calibrate these parameters against modelled latent heat would compromise our aim to use independent data for validation of the model. An alternative would be to use radiation data to estimate the time lag, but doing so also creates a dependence between the model and the validation data, because the same radiation data are also used as input in the model. Any other parametrization would be highly subjective. For this reason, we did not account for the time lag.
The sensitivity of the model to the most relevant input variables and parameters was calculated with an error propagation analysis, assuming all errors were uncorrelated. The variance of the model prediction $\sigma_{y}^{2}$ of an output variable $y$ can be calculated from the variances of the variables and parameters $x$ as:

$\sigma_{y}^{2}=\sum_{i} \sigma_{x}^{2}\left(\frac{\delta y}{\delta x}\right)^{2}$

The greatest uncertainty in the input variables is the vapour pressure deficit, which was measured at $2 \mathrm{~m}$ height rather than in or above the canopy. For four weeks at the end of the growing season in 2004 , the instrument for temperature and relative humidity was moved to just above the canopy at $9 \mathrm{~m}$ height at the south plot. A comparison with measurements before and after relocation of the instrument with data of the other plots showed that both temperature and relative humidity are lower above than below the canopy. The net effect was that vapour pressure deficit was $<2 \mathrm{hPa}$ higher above than below the canopy. At the north and the west plot, the effect might have been larger because of the taller trees and the denser canopy. In the sensitivity study, we assumed $\sigma_{e_{s}-e}=3 \mathrm{hPa}$. The greatest uncertainty in the biochemical parameters is the maximum carboxylation capacity $V_{c m}$. The accuracy of $V_{c m}$ depends on the accuracy of nitrogen measurements and the relation with leaf chamber photosynthesis measurements. Based on the confidence intervals of nitrogen and leaf chamber photosynthesis measurements and the coarse relationship between nitrogen content and $V_{c m}$, we assumed $\sigma_{V_{c m}}=10 \mu \mathrm{mol} \mathrm{m}^{-2} \mathrm{~s}^{-1}$, which is about $20 \%$ of the actual values.

Table 5 shows the sensitivity of the mean value of the fluxes of water and carbon dioxide to variations in $e_{s}-e$, $V_{c m}, \Lambda$ and $L$, absolute and as a percentage of the actual values. In the table we present standard deviations instead of variances. The difference between modelled and measured latent heat flux (Fig. 9) is smaller than the standard deviation of the error of the model prediction, i.e. the difference between modelled and measured latent heat falls within the accuracy of the parameter values and input variables. Thus, there is no reason to improve the accuracy of the physical model description itself. The uncertainty of the vapour pressure alone is insufficient to explain the difference between measured and modelled latent heat flux.

The direct effect of climate and the effect of biochemical parameters on the fluxes can be separated by the following modelling experiment. The north and the south slope have different climate conditions, and also different biochemical parameters. In one experiment, we reverse the meteorological variables at the north and the south plot while leaving the biochemical parameters the same, and in another experiment, we reverse the leaves of the north and the south plot while leaving the weather conditions the same. Figure 12 shows the result of these model experiments for the surface conductance. The bold curve is the reference scenario, as in Fig. 9, 

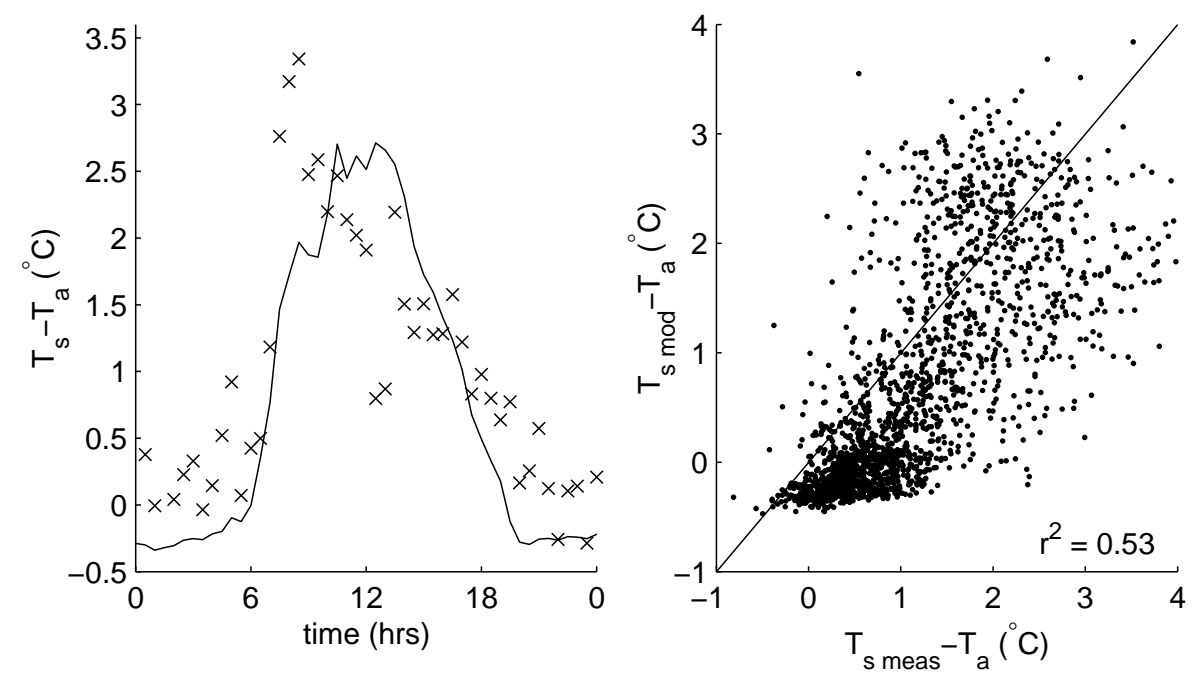

Fig. 11. Diurnal cycle of the measured (x) and modelled (line) difference between surface and air temperature at the south plot on 27 June 2004 (left), and the modelled versus the measured difference between surface and air temperature for half hourly values between 29 May and 8 July 2004 (right).

the fine line is the model where vapour pressure deficit, temperature, incoming radiation and aspect have been reversed, and the dashed line the model where parameters $V_{c m}, J_{m}$ and $\Lambda$ have been reversed. Reversing the parameters has a greater effect on surface conductance than reversing the meteorological variables. Reversing the biochemical parameters results in a large change of the magnitude of surface conductance, but a similar shape of the diurnal cycle. Reversing the meteorological variables also changes the shape of the diurnal cycle, especially the hour of the peak.

Wilson et al. (2003) studied the time lag between the peaks of radiation and the fluxes of carbon and latent heat for different climates. The time lag between the the peak of radiation and surface conductance we find is for the south plot similar to what they found for Mediterranean forests, and for the north plot similar to what they found for boreal forests. Our results indicate that this difference is mainly caused by the diurnal cycles of radiation, temperature and vapour pressure deficit.

The large effect of the spatial variations of biochemical parameters on the fluxes suggests that models which use uniform biochemical parameters would not predict the observed spatial variability of the fluxes. If average biochemical parameters are used for the north and the south plot, then surface conductance is overestimated at the south plot and underestimated at the north plot.

Although we demonstrated that spatial variations in biochemical parameters are important, we did not address the questions why biochemical parameters vary among the plots the way they do, and whether we can predict spatial patterns. Biochemical parameters are functions of environmental conditions: water potentials in soil and air, the availability of wa- ter and nutrients and temporal variations therein, and stand age, succession, pests and diseases and anthropogenic influence. A model to explain biochemical parameters from long term climate will be the subject of a separate study.

\section{Conclusions}

This study showed that both the magnitude and the shape of the diurnal cycle of transpiration and stomatal conductance can be calculated from measurements of leaf nitrogen, ${ }^{13} \mathrm{C}$ isotope discrimination and leaf photosynthesis measurements. Although the data, due to uncertainty in photosynthetic capacity, do not allow for an exact quantification, a sensitivity analysis showed that the diurnal cycles were more strongly affected by spatial variations in vegetation parameters than by meteorological variables. This indicates that topography induced variations in vegetation parameters are of at least equal importance for the fluxes as topography induced variations in radiation, humidity and temperature.

\section{Appendix A}

\section{Cowan-Farquhar model after Arneth et al. (2002)}

In their Appendix A, Arneth et al. (2002) present a solution of the model of combined model of Farquhar et al. (1980) for photosynthesis, the diffusion equations and the model of Cowan (1977). Combining Eqs. (1), (2), (3) and (4), gives two solutions for $C_{i}$ : one for enzyme limited photosynthesis, 

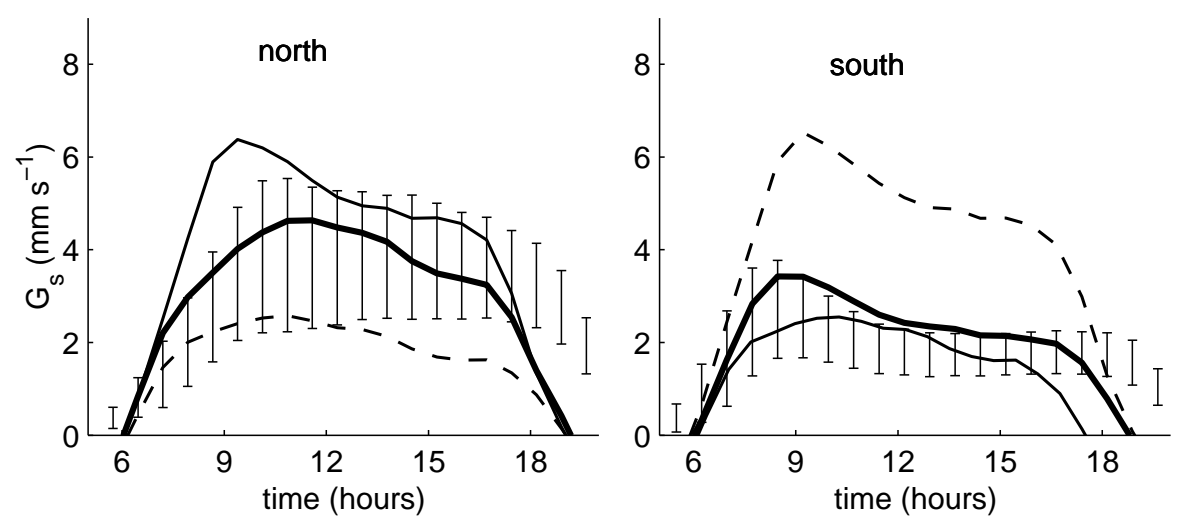

Fig. 12. Modelled and measured surface conductance for the north and the south plot, as in Fig. 9 (bold line), modelled surface conductance after reversing aspect, radiation, temperature and vapour pressure deficit of the north and south plot (fine line), and after reversing $V_{c m}, J_{m}$ and $\Lambda$ of the north and south plot (dashed line).

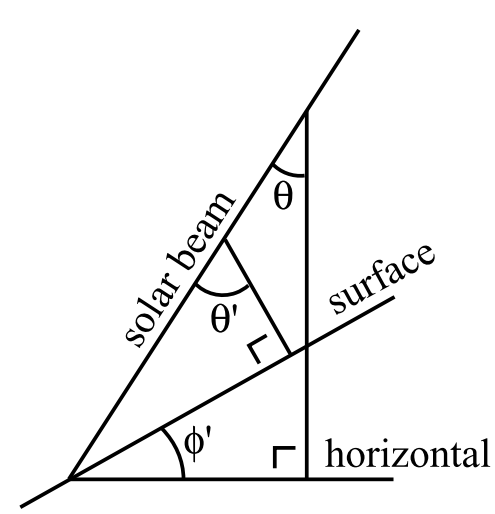

Fig. 13. Definition sketch of the zenith angle $\theta$, the angle of the surface in the plane of the direct light beam $\phi^{\prime}$, and the modified zenith angle $\theta^{\prime}$ for sloped terrain.

and one for electron limited photosynthesis. In both cases, the equation for $C_{i}$ is quadratic:

$k_{2} C_{i}^{2}+k_{1} C_{i}+k_{0}=0$

where

$$
\begin{array}{r}
k_{2}=\Lambda+\frac{1.6 D}{k^{\prime}+\Gamma^{*}} \\
k_{1}=1.6 D-2 C_{a} \Lambda+\frac{1.6 D\left(\Gamma^{*}-k^{\prime}\right)}{k^{\prime}+\Gamma^{*}} \\
k_{0}=\left(\Lambda C_{a}-1.6 D\right) C_{a}+\frac{1.6 D \Gamma^{*} k^{\prime}}{k^{\prime}+\Gamma^{*}} \\
k^{\prime}=K_{c}\left(1+O / K_{o}\right)
\end{array}
$$

for the enzyme limited case and

$$
k_{2}=\Lambda-\frac{1.6 D}{3 \Gamma^{*}}
$$

Biogeosciences, 4, 137-154, 2007

$$
\begin{array}{r}
k_{1}=1.6 D-2 C_{a} \Lambda+\frac{1.6 D \Gamma^{*}}{3 \Gamma^{*}} \\
k_{0}=\left(\Lambda C_{a}-1.6 D\right) C_{a}+\frac{1.6 D 2 \Gamma^{* 2}}{3 \Gamma^{*}}
\end{array}
$$

for the electron limited case.

\section{Appendix B}

\section{Light distribution model}

The extinction of both indirect and direct light in a canopy is calculated analogous to light absorption in homogeneous media with the law of Lambert-Beer:

$\frac{I(l)}{I_{0}}=\exp ^{-\kappa I}$

where $I$ light intensity, $l$ the depth in the canopy in units of $L$ from the top of the canopy and $\kappa$ an extinction coefficient, which depends on the zenith angle of the light beam $\theta$ and the orientation of the leaves. The orientation of the leaves is expressed by the ellipsoidal leaf angle distribution parameter $x$, where $x<1$ for mainly vertical leaves, $x=1$ for a spherical leaf distribution or $x>1$ for mainly horizontal leaves. The extinction coefficient $\kappa$ is (Campbell, 1986):

$$
\begin{aligned}
& \kappa(x, \theta)=\frac{\sqrt{x^{2}+\tan ^{2}(\theta)^{2}}}{x+1 /\left(2 \epsilon_{1} x\right) \ln \left[\left(1+\epsilon_{1}\right) /\left(1-\epsilon_{1}\right)\right]} \quad \text { if } x>1 \\
& \kappa(x, \theta)=\kappa=\sqrt{x^{2}+\tan ^{2}(\theta)^{2}} \quad \text { if } x=1 \\
& \kappa(x, \theta)=\frac{\sqrt{x^{2}+\tan ^{2}(\theta)^{2}}}{x+\arcsin \left(\epsilon_{2}\right) / \epsilon_{2}} \quad \text { if } x<1 \\
& \text { where } \epsilon_{1}=\sqrt{1-1 / x^{2}} \text { and } \epsilon_{2}=\sqrt{1-x^{2}}
\end{aligned}
$$


The extinction coefficients for indirect and direct light are different, because they origin from a different directions. The calculation of the extinction of direct light is straightforward, but the extinction of indirect light must be calculated by integration of Eq. (B1) and (B2) over the sky area. In practice, this results in an extinction coefficient of 0.7 if $x=1$, independent of geographical location, time of the year or time of the day.

In terrains of steep topography, the penetration of direct light into the canopy is different from that in flat areas. To include the effect of topography, a modified zenith angle is used in Eq. (B2). The coordinate system is rotated such that the surface becomes horizontal, and the zenith angle is calculated for the rotated coordinate system. A sloped surface is described by its steepest angle $\phi$ and the orientation of the slope $\omega$, which is the horizontal direction of the steepest downward slope, measured clockwise from north. The angle of the surface in the plane of the direct light beam and the vertical $\phi^{\prime}$, is defined as (Fig. 13):

$\phi^{\prime}=\arctan \left(\tan (\phi) \cos \left(\omega_{\mathrm{s}}-\omega\right)\right)$

where $\omega_{\mathrm{s}}$ the hour angle of the sun. The rotated zenith angle, $\theta^{\prime}$, is defined as the angle between the vector perpendicular to the slope and the solar beam, i.e.:

$\theta^{\prime}=\theta+\phi^{\prime}$

In the calculation of the vertical profile of light in the canopy with Eqs. (B1) and (B2), $\theta^{\prime}$ is used instead of $\theta$. By doing so, it is implicitly assumed that leaf angle distribution $x$ is unaffected by the coordinate rotation. This is an acceptable assumption if leaf angle distribution is spherical, but may not be acceptable if leaf angle distribution is strongly erectophile or planophile. In this study, it is assumed that $x=1$.

It is assumed that leaves are either sunlit or shaded. The effect of a partial eclipse due to the fact that direct radiation does not origin from a point source, or due to light bending over edges of leaves, is ignored. Sunlit leaves receive direct and diffuse light, shaded leaves receive only diffuse light. Scattering and transmission of direct light is ignored, and it is assumed that reflected direct light does not meet other leaves on its way back to the atmosphere. The fractions of sunlit leaves $f_{\mathrm{e}}$, and shaded leaves $f_{\mathrm{s}}$, are functions of depth in the canopy $l$ in units of leaf area index:

$f_{\mathrm{e}}(l)=\frac{I_{\mathrm{d}}(l)}{I_{\mathrm{d} 0}}$

$f_{\mathrm{s}}=1-f_{\mathrm{e}}$

where $I_{\mathrm{d} 0}$ the intensity of ambient direct light. The intensities of irradiance on the two fractions are:

$I_{\mathrm{e}}(l)=I_{\mathrm{d} 0}+I_{\mathrm{i}}(l)$

$I_{\mathrm{s}}(l)=I_{\mathrm{i}}(l)$
Total light intensity at depth $l$ in the canopy is:

$I(l)=f_{\mathrm{e}} I_{\mathrm{e}}(l)+f_{\mathrm{s}} I_{\mathrm{s}}(l)=I_{\mathrm{i}}(l)+I_{\mathrm{d}}(l)$

The exposed and shaded fractions and the irradiance on the fractions for the whole canopy are calculated by integrating Eqs. (B5) to (B8) over the leaf area index. In this study, the integration was done numerically using intervals of units leaf area index of 0.1 .

Acknowledgements. The authors thank J. de Lange, R. Lootens, K. de Bruine and H. Visch of the Vrije Universiteit (VU) for developing the sapflow sensors and other equipment, M. Groen (VU) for his technical support, M. Hooyen, S. Verdegaal, M. Konert, H. Vonhof and N. Slimmen (VU) for laboratory analyses, F. Batic of the Universitity of Ljubljana (Lj), R. Aerts and P. van Bodegom (VU) for allowing me to use their equipment, L. Globevnik of the institute for Water in Ljubljana for her administrative support, V. Zupanc and M. Padenik (Lj) for their work in the field, Peter for climbing the trees, and the reviewers for their useful comments.

Edited by: T. Laurila

\section{References}

Arneth, A., Lloyd, J., Šantrüčková, H., Bird, M., Grigoryev, S., Kalschnikov, Y., Gleixner, G., and Schulze, E.-D.: Response of central Siberian Scots pine to soil water deficit and long-term trends in atmospheric $\mathrm{CO}_{2}$ concentration, Global Biochem. Cycles, 16, 5/1-5/13, doi:10.1029/2000GB001374, 2002.

Campbell, G.: Extinction coefficients for radiation in plant canopies calculated using an ellipsoidal inclination angle distribution, Agric. For. Meteorol., 36, 317-321, 1986.

Cowan, I.: Stomatal behaviour and environment, Adv. Bot. Res., 4, 117-228, 1977.

Cowan, I.: Economics of carbon fixation in higher plants, in: On the economy of plant form and function, edited by: Givnish, T. J., Cambridge University Press, Cambridge, UK, pp. 133-170, 1986.

Cowan, I. and Farquhar, G.: Stomatal function in relation to leaf metabolism and environment, Soc. Exp. Biol. Symp., 31, 471505, 1977.

Damesin, C. and Rambal, S.: Field study of leaf photosynthetic performance by a Mediterranean deciduous oak tree (Quercus pubescens) during a severe summer drought, New Phytol., 131, 159-167, doi:10.1111/j.1469-8137.1995.tb05717.x, 1995.

De Pury, D. and Farquhar, G.: Simple scaling of photosynthesis from leaves to canopies without the errors of big-leave models, Plant Cell Environ., 20, 237-557, 1997.

Farquhar, G. and Richards, R.: Isotopic composition of plant carbon correlates with water-use efficiency of what genotypes, Austr. J. Plant Physiol., 11, 191-210, 1984.

Farquhar, G. and Sharkey, T.: Stomatal Conductance and Photosynthesis, Ann. Rev. Plant. Physiol., 33, 317-345, doi:10.1146/ annurev.pp.33.060182.001533, 1982.

Farquhar, G., von Caemmerer, S., and Berry, J.: A biochemical model of photosynthetic $\mathrm{CO}_{2}$ assimilation in leaves of $\mathrm{C}_{3}$ species, Planta, 149, 78-90, 1980. 
Farquhar, G., O'Leary, M., and Berry, J.: On the relationship between carbon isotope discrimination and the intercellular carbon dioxide concentration in leaves, Austr. J. Plant Physiol., 9, 121137, 1982.

Farquhar, G., Ehleringer, J., and Hubick, K.: Carbon isotope discrimination and photosynthesis, Annu. Rev. Plant Physiol. Plant Mol. Biol., 40, 503-537, 1989.

Field, C. and Mooney, H.: The photosynthesis-nitrogen relationship in wild plants, in: On the Economy of Plant Form and Function, edited by: Givnish, T. J., Cambridge University Press, Cambridge, UK, pp. 25-55, 1986.

Granier, A.: Mesure du flux de sève brute dans le tronc du Douglas par une nouvelle méthode thermique, Ann. Sci. Forest, 44, 1-14, 1987.

Harley, P. and Baldocchi, D.: Scaling carbon dioxide and water vapour exchange from leaf to canopy in a deciduous forest. I. Leaf model parameterization, Plant Cell Environ., 18, 1146$1156,1995$.

Hetherington, A. and Woodward, F.: The role of stomata in sensing and driving environmental change, Nature, 424, 901-908, 2003.

Jones, H.: Stomatal control of photosynthesis and transpiration, J. Expl. Bot., 49, 387-398, 1998.

Keesstra, S.: The effects of natural reforestation on the hydrology, river morphology and sediment budget of the Dragonja catchment in SW Slovenia, Ph.D. thesis, Vrije Universiteit Amsterdam, The Netherlands, 2006.

Lambers, H., Stuart Chapin III, F., and Pons, T.: Plant Physiological Ecology, Springer Verlag, New York, 2000.

Leuning, R.: A critical appraisal of a combined stomatalphotoynthesis model for C3 plants, Plant Cell Environ., 18, 339355, 1995.

Leuning, R., Kelliher, F., Pury, D. D., and Schulze, E. D.: Leaf nitrogen, photosynthesis, conductance and transpiration: scaling from leaves to canopies, Plant Cell Environ., 18, 1183-1200, 1995.

Lloyd, J. and Farquhar, G.: $13 \mathrm{C}$ discrimination during $\mathrm{CO}_{2}$ assimilation by the terrestrial biosphere, Oecologia, 99, 201-215, 1994.

Lloyd, J., Grace, J., Miranda, A., Meir, P., Wong, S., Miranda, H., Wright, I., Gash, J., and McIntyre, J.: A simple calibrated model of Amazon rainforest productivity based on leaf biochemical properties, Plant Cell Environ., 18, 1129-1145, 1995.

Makela, A., Berninger, F., and Hari, P.: Optimal control of gas exchange during drought: Theoretical analysis, Ann. Bot., 77, 461467, 1996.
Mencuccini, M.: The ecological significance of long-distance water transport: short-term regulation, long-term acclimation and the hydraulic costs of stature across plant life forms, Plant Cell Environ., 26, 163-182, 2003.

Niinemets, U.: Research review. Components of leaf dry mass per area thickness and density - alter leaf photosynthetic capacity in reverse directions in woody plants, New Phythol., 144, 35-47, doi:10.1046/j.1469-8137.1999.00466.x, 1999.

Reich, P. B., Walters, M. B., Ellsworth, D. S., Vose, J. M., Violin, J. C., Gresham, C., and Bowman, W. D.: Generality of leaf trait relationships: a test across six biomes, Ecology, 80, 1955-1969, 1999.

Schulze, E., Cermàk, J., Matyssek, R., Penka, M., Zimmermann, R., Vasicek, F., Gries, W., and Kucera, J.: Canopy transpiration and water fluxes in the xylem of the trunk of Larix and Picea trees a comparison xylem flow, porometer and cuvette measurements, Oecologia, 66, 475-483, 1985.

Sellers, P., Dickinson, R., Randall, D., Betts, A., Hall, F., Berry, J., Collatz, G., Denning, A., Mooney, H., Nobre, C., Sato, N., Field, C., and Henderson-Sellers, A.: Modeling the Exchanges of Energy, Water, and Carbon Between Continents and the Atmosphere, Science, 275, 502-509, 1997.

Tuzet, A., Perrier, A., and Leuning, R.: A coupled model of stomatal conductance, photosynthesis and transpiration, Plant Cell Environ., 26, 1097-1116, 2003.

Tyree, M. and Sperry, J.: Do woody plants operate near the point of catastrophic xylem dysfunction caused by dynamic water stress? Answers from a model, Plant Physiol., 88, 574-580, 1988.

Wilson, K., Baldocchi, D., Falge, E., Aubinet, M., Berbigier, P., Bernhofer, C., Dolman, A., Field, C., Goldstein, A., Granier, A., Hollinger, D., Katul, G., Law, B., Meyers, T., Moncrieff, J., Monson, R., Tenhunen, J., Valentini, R., Verma, S., and Wofsy, S.: Diurnal centroid of ecosystem energy and carbon fluxes at FLUXNET sites, J. Geophys. Res., 108(D21), 4664, doi:10.1029/2001JD001349, 2003.

Wong, S., Cowan, I., and Farquhar, G.: Stomatal conductance correlates with photosynthetic capacity, Nature, 282, 424-282, 1979.

Zhang, J. and Davies, W.: Abscisic acid produced in dehydrating roots may enable the plant to measure the water status of the soil, Plant Cell Environ., 12, 73-81, 1989. 